Working Paper/Document de travail 2011-16

\title{
Real-Time Forecasts of the Real Price of Oil
}

\author{
by Christiane Baumeister and Lutz Kilian
}


Bank of Canada Working Paper 2011-16

August 2011

\title{
Real-Time Forecasts of the Real Price of Oil
}

\author{
by
}

\author{
Christiane Baumeister ${ }^{1}$ and Lutz Kilian ${ }^{2}$ \\ IInternational Economic Analysis Department \\ Bank of Canada \\ Ottawa, Ontario, Canada K1A 0G9 \\ 2Department of Economics \\ University of Michigan \\ Ann Arbor, Ml 48109-1220 \\ Corresponding author: Ikilian@umich.edu
}

Bank of Canada working papers are theoretical or empirical works-in-progress on subjects in economics and finance. The views expressed in this paper are those of the authors. No responsibility for them should be attributed to the Bank of Canada. 


\section{Acknowledgements}

We thank Ron Alquist, Tatevik Sekhposyan and Garima Vasishtha for helpful comments. William Wu provided excellent research assistance. 


\begin{abstract}
We construct a monthly real-time data set consisting of vintages for 1991.1-2010.12 that is suitable for generating forecasts of the real price of oil from a variety of models. We document that revisions of the data typically represent news, and we introduce backcasting and nowcasting techniques to fill gaps in the real-time data. We show that real-time forecasts of the real price of oil can be more accurate than the no-change forecast at horizons up to one year. In some cases real-time MSPE reductions may be as high as 25 percent one month ahead and 24 percent three months ahead. This result is in striking contrast to related results in the literature for asset prices. In particular, recursive vector autoregressive (VAR) forecasts based on global oil market variables tend to have lower MSPE at short horizons than forecasts based on oil futures prices, forecasts based on AR and ARMA models, and the no-change forecast. In addition, these VAR models have consistently higher directional accuracy. We demonstrate how with additional identifying assumptions such VAR models may be used not only to understand historical fluctuations in the real price of oil, but to construct conditional forecasts that reflect hypothetical scenarios about future demand and supply conditions in the market for crude oil. These tools are designed to allow forecasters to interpret their oil price forecast in light of economic models and to evaluate its sensitivity to alternative assumptions.
\end{abstract}

JEL classification: Q43, C53, E32

Bank classification: Econometric and statistical methods; International topics

\title{
Résumé
}

Les auteurs construisent un ensemble de données mensuelles en temps réel qui regroupe les cuvées relatives à la période allant de janvier 1991 à décembre 2010 et qui se prête à la génération de prévisions du prix réel du pétrole à partir de divers types de modèles. Ils montrent que les révisions de données correspondent le plus souvent à l'arrivée de nouvelles informations, et ils suppléent aux données en temps réel manquantes en employant des techniques de prévision pour la période précédente et la période courante. Les auteurs constatent que les prévisions en temps réel du prix réel du pétrole peuvent être plus précises que celles tirées d'une marche aléatoire à des horizons ne dépassant pas un an. Dans certains cas, la réduction de l'erreur quadratique moyenne de prévision en temps réel peut atteindre 25 \% à l'horizon d'un mois et $24 \%$ à l'horizon de trois mois, ce qui contraste fortement avec les résultats présentés dans la littérature sur les prix des actifs. Plus particulièrement, les prévisions récursives obtenues avec des modèles vectoriels autorégressifs (VAR) qui incluent des variables du marché mondial du pétrole donnent lieu en général à une réduction de l'erreur quadratique moyenne de prévision aux horizons rapprochés par rapport aux cours à terme du pétrole, aux modèles autorégressifs, aux modèles autorégressifs à moyenne mobile et à la marche aléatoire. De plus, ces modèles VAR produisent des prévisions systématiquement meilleures concernant le sens des variations. Les auteurs démontrent comment, par l'ajout d’hypothèses 
d'identification, ces modèles permettent non seulement de comprendre les fluctuations antérieures du prix réel du pétrole, mais aussi de construire des prévisions conditionnelles reflétant des scénarios hypothétiques au sujet de la demande et des conditions d'approvisionnement futures sur le marché du pétrole brut. Ces outils sont conçus pour que les prévisionnistes puissent interpréter leurs résultats à la lumière des modèles économiques et évaluer la sensibilité de leurs prévisions à des hypothèses différentes.

Classification JEL : Q43, C53, E32

Classification de la Banque : Méthodes économétriques et statistiques; Questions internationales 


\section{Introduction}

The real-time nature of data used in forecasting has received increasing attention in recent years (see, e.g., Clements and Galvão 2010; Croushore 2006, 2011). Although the real price of oil is one of the key variables in the model-based macroeconomic projections generated by central banks, private sector forecasters, and international organizations, there have been no studies to date of how best to forecast the real price of oil in real time. One likely reason is that - unlike for U.S. domestic macroeconomic aggregates - there is no real-time data set for variables relevant to forecasting the real price of oil. ${ }^{1}$ In this paper we remedy this situation by constructing from the original data sources a comprehensive monthly real-time data set consisting of vintages for 1991.1 through 2010.12, each covering data extending back to 1973.1. This data set allows the construction of real-time forecasts of the real price of oil from a variety of models. Both backcasting and nowcasting techniques are used to fill gaps in the real-time data. In section 2, we show that revisions of most oil market data represent "news" as defined in De Jong (1987) and Faust, Rogers, and Wright (2005). In other words, there is little scope for improving forecasts by modeling the revision process. This fact facilitates the construction of nowcasts to fill in gaps in the availability of real-time data for most series.

In section 3, we use this data set to provide evidence that real oil price forecasts can be more accurate than the no-change forecast at horizons up to one year. We present results both for the U.S. refiners' acquisition cost for crude oil imports, which may be viewed as a proxy for the price of oil in global markets, and for the WTI spot price which receives most attention in the media. $^{2}$ The evaluation window is 1992.1-2010.6. Our evaluation criteria are both the MSPE of the forecasts and their directional accuracy. We consider a variety of forecasting methods including versions of methods that have been shown to work well in the related context of forecasting the nominal price of oil (see, e.g., Alquist, Kilian, and Vigfusson 2011). We find that many forecasting methods perform well compared with the no-change forecast at horizons up to one year. With some forecasting methods, real-time MSPE reductions may be as high as 25 percent one month ahead and 24 percent three months ahead. This result is in striking contrast to related results in the literature for real exchange rates or real stock returns. In particular, we show

\footnotetext{
${ }^{1}$ Neither the real-time data set repository maintained by the Federal Reserve Bank of Philadelphia nor the ALFRED data base maintained by the Federal Reserve Bank of St. Louis include such data. Nor does the U.S. Energy Information Administration provide any real-time data sets.

${ }^{2}$ We do not consider the Brent price given the limited time span for which that price has existed.
} 
that recursive vector autoregressive (VAR) forecasts based on global oil market variables tend to have lower MSPEs at short horizons than forecasts based on oil futures prices, forecasts based on AR and ARMA models, and the no-change forecast. In addition, these VAR models have consistently and often significantly higher directional accuracy with success ratios as high as $65 \%$ in real time in some cases. Such success ratios are high by the standards of the empirical finance literature (see, e.g., Pesaran and Timmermann 1995).

Section 3 also contrasts the real-time forecasting results with results for the same forecasting models based on ex-post revised data. It is not obvious ex ante whether models based on ex-post revised data should forecast more accurately than models based on real-time data. For example, Faust, Rogers, and Wright (2003) suggest that real-time forecasts may be more accurate if agents' behavior reflects real-time expectations. We find that there are no further gains in forecast accuracy from using ex-post revised data when using the WTI price, but substantially larger gains when using the refiners' acquisition cost for imported oil. In the latter case, some VAR models produce MSPE gains as high as 33 percent at the one-month horizon, 22 percent at the three-month horizon, and 3\% at the six-month horizon. This raises the question of which aspect of the data collection statistical agencies should focus on to improve the overall forecast accuracy for the real refiners' acquisition cost. We find that improving the timely availability of accurate data on the nominal price of oil has by far the highest payoff. For the U.S. refiners' acquisition cost for imports, replacing the nominal price by ex-post revised data alone suffices to generate forecasts almost as accurate as if all data were ex-post revised and available in real time. None of the other variables has such a large impact. This conclusion is further corroborated by the fact that for the WTI price, which is not subject to data revisions and available without delay, the difference between the VAR forecast accuracy with real-time data and with ex-post revised data is negligible.

In section 4, we contrast the real-time forecast accuracy of regression-based models with that of alternative forecasting methods based on oil futures prices or non-oil industrial commodity prices. We show that models based on oil futures prices do not produce significant MSPE reductions and have lower directional accuracy than suitably chosen VAR models. We also make the case that VAR models have advantages over models based on industrial commodity prices alone. 
An important limitation of standard reduced-form forecasting models from a policy point of view is that they provide no insight into what is driving the forecast and do not allow the policymaker to explore alternative hypothetical forecast scenarios. Policymakers not only expect oil price forecasts to be interpretable in light of an economic model, but like to evaluate the risks associated with a baseline forecast based on an extensive analysis of how these forecasts change with changes in the underlying assumptions. In section 5, we illustrate how with additional identifying assumptions the VAR forecasting models that we already considered in section 3 may also be used to understand historical fluctuations in the real price of oil and to construct real-time conditional projections of how the oil price forecast would deviate from the unconditional forecast benchmark under hypothetical scenarios about future demand and supply conditions in the global market for crude oil. Examples of such scenarios include an unexpected surge in speculative demand triggered by civil unrest in an oil-producing country such as Libya, for example, or an unexpected resurgence of the global business cycle. These tools are designed to allow end-users to interpret oil price forecasts in light of economic models and to evaluate their sensitivity to alternative assumptions. The concluding remarks are in section 6.

\section{The Real-Time Data Set}

Unlike Carlton (2010) and Ravazzolo and Rothman (2010) our focus is not on real-time forecasting of U.S. real GDP growth on the basis of lagged oil prices, but rather on generating real-time forecasts of the real price of oil. Our analysis is more closely related to the recent literature on real-time forecasts of the nominal price of oil (see, e.g., Alquist and Kilian 2010; Alquist, Kilian, and Vigfusson 2011). Although the real price of oil is one of the key variables in the model-based macroeconomic projections generated by central banks, private sector forecasters, and international organizations, there have been no studies to date of how best to forecast the real price of oil in real time. One reason is that there is no readily available real-time data set for the variables required in forecasting the real price of oil.

Our first contribution in this paper is the construction of such a data set from a variety of sources, many of which are not available in electronic form. Our data set is monthly and includes some raw data that are available in real time and not subject to data revisions such as 1) the WTI spot price of crude oil, 2) NYMEX oil futures prices at various maturities, 3) an index of the spot price of industrial raw materials, and 4) an index of bulk dry cargo ocean shipping freight rates 
(such as the Baltic Dry Cargo Index). Our data set also includes many time series that are not available in real time. The latter time series include: 1) the nominal U.S. refiners' acquisition cost for crude oil imports, 2) world crude oil production, 3) U.S. crude oil inventories, 4) U.S. petroleum inventories, 5) OECD petroleum inventories. Finally, we collected data for the U.S. consumer price index for all urban consumers and the U.S. producer price index for crude oil.

The use of real-time data in forecasting raises two distinct complications. First, even preliminary data may become available only with a lag. Second, past data are continuously revised. Little is known about the nature of the revisions of oil market data or how these revisions and delays in data availability affect out-of-sample forecast accuracy.

\subsection{Data Sources}

Monthly averages of the daily WTI spot price were obtained from the website of the U.S. Energy Information Administration (EIA). The corresponding average NYMEX oil futures prices are from Bloomberg. The spot price index of industrial raw materials is from the Commodity Research Bureau. All other oil market data were obtained from the Monthly Energy Review published by the EIA. Prior to 1996.1 this publication is not available in electronic form. The construction of the real-time data set from the historical issues of the Monthly Energy Review is described in detail below. The nominal shipping rate data are obtained from Kilian (2009) for 1973.1 through 1984.12 and are extrapolated through 2010.12 using the Baltic Dry Cargo Index (BDI) from Bloomberg. Real-time data for the monthly U.S. consumer price index are obtained from the Economic Indicators published by the Council of Economic Advisers. These data are made available by the FRASER data base of the Federal Reserve Bank of St. Louis. Additional real-time CPI data were obtained from the macroeconomic real-time data base of the Federal Reserve Bank of Philadelphia. The U.S. producer price index for crude oil is not required in real time for our analysis and is obtained from the Bureau of Labor Statistics.

\subsection{Real-Time Data Revisions}

Each issue of the Monthly Energy Review contains the current vintage of oil market data and differs from the preceding issue in that the historical data may have been partially revised and that a new monthly observation has been added. Due to space limitations, historical data past a certain number of months are no longer included in the current report (nor are these historical 
data available in electronic form). In constructing the real-time data set we assume that no further revisions occur to these historical data.

Ex-post revised data are constructed from the most up-to-date data downloaded from the EIA website. The most recent data set available at the time our study was written was for 2010.12. Because the most recent data are still preliminary, we discarded the last six months of data. The remaining data for 1973.1-2010.6 are treated as ex-post revised data when evaluating the forecasting accuracy of the candidate models. Although some of the data close to the end of this sample will not be completely revised after six months, the remaining revisions are likely to be small enough to be ignored in the interest of a larger evaluation sample that includes the recent period of oil price volatility.

The difference between the initial release for a given date and the ex-post revised observation for that date can be decomposed further. We distinguish between in-report revisions and post-report revisions of each time series. In-report revisions are defined as the log-difference between the value shown in the most recent vintage available for that date in subsequent issues of the Monthly Energy Review and the value reported on the first release date. Post-report revisions refer to the log-difference between the ex-post revised value and the corresponding value in the most recent vintage available in subsequent issues of the Monthly Energy Review.

Exhibit 1 provides selected descriptive statistics concerning the nature of the data revisions for each time series. The average number of revisions ranges from 1 for the U.S. refiners' acquisition cost for crude oil imports to 9 in the global crude oil production data. Most revisions occur one month after the first release, but revisions may continue for several years in some cases. For U.S. oil market data revisions are complete within two years. The relative frequency of revisions declines over time, but not necessarily monotonically.

For all oil market series, we find that the post-report revisions are essentially zero, lending credence to our assumption that historical data are not revised further once they are no longer reported in the Monthly Energy Review. Moreover, the in-report revisions are near zero on average with very small standard deviations (smaller than $0.1 \%$ in all cases), indicating that realtime forecasts could not be improved by adjusting forecasts by a constant representing the revision bias. This does not mean that the preliminary data releases are necessarily efficient forecasts of the final releases, but, as will be shown in section 3.3, for most series the quality of the preliminary data makes little difference in forecasting the real price of oil. 


\subsection{Backcasting}

Our objective is to construct a real-time data set consisting of vintages for 1991.1 through 2010.12, each covering data extending back to 1973.1. The starting date of 1991.1 for the first vintage was chosen because the Monthly Energy Review was not issued between October and December of 1990, creating a gap in the real-time data.

One complication in creating the real-time data set is that each vintage as reported by the EIA only includes data for at most three years. For example, the 1991.1 issue includes data as far back as 1988.1. This means that the pre-1988.1 data for all vintages have to be approximated by the ex-post revised data. Given that the post-report revisions, as shown in section 2.2, are zero or negligible even for more recent data, this backcasting approach is likely to be a good approximation.

In addition, as we move from one Monthly Energy Review to the next, some of the earlier observations are no longer reported. There are two alternative approaches to filling in these missing data. One approach is to rely on ex-post revised data. The other approach postulates that, once observations are no longer reported, no further data revisions occur, so we can use the most recent data from earlier vintages to fill in the gaps in the current vintage. Preliminary forecast evaluations indicated that neither approach results in systematically more accurate out-of-sample forecasts than the other and that the differences in results are negligible. Throughout this paper we employ the second approach.

In constructing the monthly U.S. refiners' acquisition cost for crude oil imports a further complication arises because these data are only available starting in 1974.1. We followed the procedure outlined in Mork (1989, p. 741) for extrapolating the refiners' acquisition cost backwards to 1973.1 . This procedure involves scaling the monthly percent rate of change in the U.S. crude oil producer price index for 1973.1-1974.1 by the ratio of the growth rate in the annual refiners' acquisition cost over the growth rate in the annual U.S. producer price index for crude oil.

Consistent series for OECD petroleum stocks are not available prior to 1987.12. We therefore extrapolate the percent change in OECD inventories backwards at the rate of growth of U.S. petroleum inventories, following Kilian and Murphy (2010). For the post-1987.12 period, U.S. and OECD petroleum inventory growth rates are highly correlated. We also adjust the realtime OECD petroleum inventory data to account for changes in the set of OECD members 
reporting inventories in December 2001. This adjustment is necessary to preserve the consistency of the real-time and the ex-post revised inventory data. The procedure is to add expost revised data from the EIA on the petroleum inventories of these countries in constructing real-time equivalents of the OECD petroleum inventory data prior to the change in classification. Likewise, we adjust the real-time OECD petroleum inventory data contained in the pre-June 1993 issues of the Monthly Energy Review to reflect the addition of East Germany.

Finally, in constructing real-time CPI data we face the problem that the CEA only reports real-time CPI data for the 12 most recent months of each vintage. We fill in the missing data back to 1973.1 based on quarterly vintages of monthly real-time CPI data from the Federal Reserve Bank of Philadelphia, exploiting the fact that observations shown in each vintage represent the data that were available in the middle of the quarter.

\subsection{Data Transformations}

The real price of oil is constructed by deflating the nominal price of oil by the U.S. consumer price index. World oil production is expressed in growth rates. Following Kilian and Murphy (2010), a proxy for the change in world crude oil inventories is constructed by scaling U.S. crude oil inventories by the ratio of OECD over U.S. petroleum inventories. This approximation is required because there are no monthly crude oil inventory data for other countries. Finally, as is standard in the literature, the measure of global real activity is constructed by cumulating the growth rate of the index of nominal shipping rates, the resulting nominal index is deflated by the U.S. consumer price index, and a linear deterministic trend representing increasing returns to scale in ocean shipping is removed from the real index (see, e.g., Kilian 2009). The resulting index is designed to capture business cycle fluctuations in global industrial commodity markets. In constructing the real-time version of this index of global real activity, the linear deterministic trend is recursively re-estimated in real time.

An interesting question is whether data revisions in these transformed real-time series represent news or whether they could have been predicted based on the initial data release. We focus on world oil production growth, the change in global crude oil inventories, and the real refiners' acquisition cost for crude oil imports. ${ }^{3}$ Let $R_{t} \equiv X_{t}^{f}-X_{t}^{p}$, where $X_{t}^{p}$ denotes the

\footnotetext{
${ }^{3}$ The corresponding revisions in the real WTI price are effectively negligible, making further analysis of that series moot. We also excluded the global real activity index from the analysis. Because the underlying shipping rates are
} 
preliminary data release for a given time series and $X_{t}^{f}$ the final release. Under the news characterization, the statistical agency optimally uses all available information, so revisions of preliminary data must reflect news that arrives after the preliminary data release. This hypothesis implies that revisions must be mean zero because otherwise revisions would be predictable. It can be shown that there is no statistically significant bias in the revisions for any of the three transformed real-time variables.

As noted by Faust et al. (2005), bias is the simplest form of predictability in revision. Even in the absence of bias, however, revisions may be predictable based on preliminary data releases. A more general specification of the news hypothesis implies that $\alpha=\beta=0$ in

$$
R_{t}=\alpha+\beta X_{t}^{p}+u_{t}
$$

where $u_{t}$ may be serially correlated. Inference is based on HAC standard errors. We find that only for revisions to world crude oil production the news hypothesis can be rejected at conventional significance levels. Even in that case, the $R^{2}$ of the regression is only 3\%, however, suggesting that our ability to predict the revisions will be very limited. Additional evidence in section 3.3 will confirm this conjecture.

\subsection{Nowcasting}

A further complication arises because some of the data used in constructing the real price of oil and its predictors are only available with a delay. Exhibit 1 indicates for each series the number of missing real-time observations. In some cases, the real-time data become available with a lag as long as six months. These gaps in the real-time data have to be filled using nowcasting. We extrapolate the world oil production data based on the average rate of change in world oil production up to that point in time. The same approach is used for the U.S. consumer price index. This amounts to treating the price level as a random walk with drift. The U.S. refiners' acquisition cost for crude oil imports is extrapolated at the rate of growth of the WTI price. Not surprisingly, this approach dramatically improves out-of-sample forecast accuracy compared

spot prices not subject to revisions and because the effect of the revisions in the CPI on the index is negligible, the only real-time uncertainty in measuring global real activity arises from the trend estimate. Given that trend estimation uncertainty is not related to the data revision process, we abstract from the real activity index in studying the news hypothesis. The analysis in section 3.3 indicates that this trend estimation uncertainty has little effect on out-of-sample forecast accuracy. 
with using the no-change nowcast because it incorporates unforecastable movements in oil prices. In nowcasting the global crude oil inventory data, we treat the ratio of OECD over U.S. petroleum inventories as a random walk and extrapolate U.S. crude oil inventories at their average rate of change in the past. These nowcasting methods are designed to be simple to implement, yet accurate. In section 3.3 we provide evidence that more sophisticated nowcasting rules would not improve forecasting accuracy materially.

\section{Real-time Forecast Accuracy}

Our objective throughout this paper is to forecast the level of the real price of oil rather than the log price because it is the real price that matters to policymakers. ${ }^{4}$ Regression models are specified in logs, where appropriate, and the forecasts are exponentiated. The forecast horizon is one, three, six, nine and twelve months.

\subsection{Regression-Based Forecasts}

Table 1 summarizes the real-time forecast accuracy of ARMA and AR models of the real U.S. refiners' acquisition cost for crude oil imports and of the four-variable VAR oil market model of Kilian and Murphy (2010). The VAR model includes the percent change in global crude oil production, the Kilian (2009) measure of global real activity (in deviations from trend), the change in global crude oil inventories and the real U.S. refiners' acquisition cost for crude oil imports, as a measure of the real price of crude oil in global oil markets. Table 2 shows the results for the corresponding models based on the real WTI price. We consider fixed autoregressive lag orders of 12 and 24. Such lag orders are common in the literature on oil market VAR models. ${ }^{5}$ The autoregressive models are estimated alternatively by unrestricted least squares and by Bayesian shrinkage methods. The forecast accuracy of the latter methods depends on the choice of the prior for the model parameters. Rather than reporting results for alternative priors, as is common in related work, we rely on the data-based method of Giannone, Lenza, and Primiceri (2010) for selecting the prior in real time. This approach avoids the temptation of searching ex post for priors that generate more accurate forecasts and preserves the

\footnotetext{
${ }^{4}$ In this sense our analysis differs from related work such as Alquist, Kilian, and Vigfusson (2011), for example.

${ }^{5}$ As shown in Alquist, Kilian, and Vigfusson (2011), the forecast accuracy of AR models for the price of oil is not very sensitive to the lag order and similar results would be obtained if the lag order were selected by information criteria. Nor would differencing the real price of oil improve the forecast accuracy of the AR and ARMA models.
} 
real-time nature of the forecasting exercise. The ARMA(1,1) model is estimated numerically by Gaussian maximum likelihood methods.

Table 1a shows that all methods under consideration produce lower recursive MSPEs than the no-change forecast at least at short horizons. For example, the ARMA(1,1) model consistently reduces the MSPE by between $8 \%$ and $10 \%$ at all horizons. Similar results are obtained with the BAR(24) model. The AR(24) model is somewhat less accurate, indicating overfitting problems with the least-squares estimate. AR and BAR models with 12 lags also are somewhat less accurate, indicating the importance of including a larger number of lags.

Even larger short-run MSPE reductions are possible when using the VAR model. For example, the unrestricted VAR(12) model lowers the one-month recursive MSPE by 25\% compared with the no-change forecast and the three-month recursive MSPE by 19\%. At horizon 9 the two models are essentially tied, but at horizon 12, the MSPE reduction is still 3\%. The VAR(12) model in fact is more accurate than the corresponding BVAR(12) model. Not surprisingly, however, the forecast accuracy of the VAR(24) model is greatly improved by the use of Bayesian shrinkage estimation methods. Although the BVAR(24) model is not as accurate as the VAR(12) model by the MSPE metric, it is still much more accurate in the short run than AR or ARMA models and - unlike any other model - it offers high and often statistically significant directional accuracy at all horizons. For example, the probability of correctly predicting the direction of change is $61 \%$ at horizon 1 and $65 \%$ at horizon 3 . Even at horizon 12 it remains as high as 58\%. Based on directional accuracy alone, the BVAR(24) model would be the obvious choice among the models under consideration.

Table 2a shows that for the real WTI price as well most methods under consideration produce lower recursive MSPEs than the no-change forecast at least at short horizons. The magnitude of the forecast accuracy gains is typically somewhat smaller. For example, the ARMA(1,1) model consistently reduces the MSPE by between $6 \%$ and $8 \%$ at all horizons. Even more accurate is the BAR(24) model with MSPE reductions between $8 \%$ and $10 \%$ at all horizons. Marginally larger short-run MSPE reductions are possible when using the VAR(12) and BVAR(12) model. These models also have higher directional accuracy than AR and ARMA models. Finally, although the unrestricted VAR(24) is strictly dominated by the no-change forecast, the BVAR(24) model dominates the no-change forecast at all horizons with MSPE reductions as large as $14 \%$ at horizon $1,13 \%$ at horizon 3, 6\% at horizon 6, and 5\% at horizons 9 
and 12. As in Table 1b, the BVAR(24) model also has the highest directional accuracy among all models considered with success ratios ranging from 56\% at horizon 1 to $61 \%$ at horizon 12 .

We conclude that notwithstanding some differences between the results in Tables 1 and 2, there is strong evidence that forecasters can beat the random walk benchmark in real time. Moreover, in both cases the BVAR(24) model offers the best overall combination of low MSPE and directional accuracy. This forecasting success is perhaps unexpected given the common view that the price of oil should be viewed as an asset price and like all asset prices is inherently unpredictable. Our findings are fully consistent, however, with recent work showing that the price of oil most of the time contains only a small asset price component (see Kilian and Murphy 2010; Kilian and Vega 2011). It is also consistent with evidence that the nominal WTI price of oil is predictable based on economic fundamentals at short horizons (see Alquist, Kilian, and Vigfusson 2011).

Although we report tests of statistical significance for the success ratios in Table $1 \mathrm{~b}$ and 2b, we do not provide measures of statistical significance for the MSPE reductions in Tables 1a and 2a. The reason is that such tests are not available. The problem is that the underlying time series are not stationary because they include data that have been revised to different degrees (see, e.g., Koenig, Dolmas, and Piger 2003; Clements and Galvão 2010; Croushore 2011). This feature of the regression analysis violates the premise of standard asymptotic tests of equal predictive accuracy. Clark and McCracken (2009) recently proposed an alternative test of equal predictive accuracy for real-time data, the construction of which requires further assumptions on the nature of the data revisions and evidence that these assumptions are met in the real-time data. That test is not designed for iterated forecasts, however, and could not be applied in our context even if our real-time data satisfied the assumptions of Clark and McCracken (2009). Nor is it possible to rely on standard bootstrap methods to simulate the critical values of tests of equal predictive accuracy in our iterated real-time setting. In section 3.2, we will show, however, that the same regression models generate highly statistically significant rejections of the null of equal predictive accuracy when applied to ex-post revised data. Moreover, we will show in section 5 that some alternative forecasting methods built on data that are available in real time (and hence amenable to statistical testing) fail to generate statistically significant reductions in the MSPE both using ex-post revised and real-time data. 


\subsection{Forecast Accuracy Based on Ex-Post Revised Data}

There are four distinct reasons for investigating the forecast accuracy using ex-post revised data. First, it provides a benchmark against which we can assess how practically important the distinction between real-time forecasts and conventional forecasts is. Second, this comparison allows us to determine which aspects of the data collection, if improved, are likely to increase real-time forecast accuracy the most, as illustrated in section 3.3. Such information is particularly useful for data providers such the U.S. Energy Information Administration. Third, given the impossibility of assessing the statistical significance of the real-time MSPE reductions from iterated AR, ARMA and VAR forecasts, the use of ex-post revised data allows us to provide at least some sense of how statistically significant these reductions are likely to be. Fourth, the performance of VAR models on ex-post revised data is of independent interest when constructing conditional forecasts or forecast scenarios, as shown in section 5 . The latter scenarios must be based on our best estimate of the population dynamics rather than preliminary estimates from real-time data.

The results in Tables 3 and 4 are the counterparts of the real-time analysis in Tables 1 and 2. The only difference is that all real-time data have been replaced by ex-post revised data. We treat the data up to 2010.6 in the 2010.12 vintage as our proxy for the ex-post revised data. The implicit premise is that virtually all data revisions have taken place within half a year. This premise is largely consistent with the evidence we presented in section 2.

Table 3 for the real U.S. refiners' acquisition cost shows that using ex-post revised data there is overwhelming evidence against the random walk forecast model. The MSPE reductions are both statistically significant based on bootstrap critical values and economically significant. This conclusion is by no means self-evident because both the no-change forecasts and the regression-based forecasts tend to benefit from the availability of ex-post revised data. Hence, the recursive MSPE ratio ex ante could rise or fall.

Table 3 shows, for example, that ARMA models produce statistically significant reductions in the MSPE at all horizons. The reductions range from $22 \%$ to $8 \%$, depending on the horizon and are much larger in the short run than for real-time data. Very similar results hold for the BAR(24) model. Even more accurate in the short run is the VAR(12) model which generates statistically significant reductions of 33\% at horizon 1, 22\% at horizon 2 and $6 \%$ at horizon 3 . The BVAR(24) model by comparison has somewhat lower MSPE, but higher directional 
accuracy. Even that model still produces highly statistically significant MSPE reductions relative to the no-change forecast of $27 \%$ at horizon $1,15 \%$ at horizon 3 , and $3 \%$ at horizon 6 .

For the real WTI price in Table 4, in contrast, we find little difference between the analysis using real-time and ex-post revised data. The forecast accuracy improves only marginally when using ex-post revised data. We conclude that forecast accuracy comparisons based on the ex-post revised data are likely to be informative about the real-time forecast accuracy for the real WTI price, but not for the real U.S. refiners' acquisition cost. We also conclude that the favorable performance of many non-random walk models is likely not to be a statistical fluke.

\subsection{How Improved Data Collection Can Improve Real-Time Forecast Accuracy}

Tables 1 through 4 illustrate that abstracting from real-time data constraints has little effect on measures of forecast accuracy when forecasting the real WTI price of oil, but major effects when forecasting the real U.S. refiners' acquisition cost for imported crude oil. The problem is not so much ex-post revisions to the data used by these forecasting models, but delays in the data availability. This raises the question of which of the time series in question we should focus on in improving the real-time availability of the data.

Table 5 focuses on the example of the BVAR(24) model. We investigate how the recursive MSPE changes, as we replace one variable at a time in the real-time model by the expost revised series. This thought experiment involves a hypothetical world, in which the statistical agency in question is able to deliver this one series in a timely and accurate manner, while all other series remain unchanged and subject to real-time data constraints. For the reader's convenience, we also include the limiting case in which all VAR time series are ex-post revised and in which none of these series is ex-post revised.

The first column of Table 5 focuses on the real U.S. refiners' acquisition cost for imports. If we replace the real-time data on global oil production in the VAR model by ex-post revised data, for example, the one-month ahead MSPE ratio remains virtually unchanged, indicating that efforts to improve the real-time availability of this time series would have little payoff. Similar conclusions apply to the data on global real economic activity, the U.S. consumer price index, global and U.S. crude oil inventories. The only time series that, if available in real time, would allow a substantial improvement in real-time forecast accuracy is the real price of oil. In fact, 
most of that reduction in the MSPE is associated with more timely and accurate information about the nominal U.S. refiners' acquisition cost. With that information alone the MSPE ratio relative to the no-change forecast would drop from 0.806 to 0.760 , compared to 0.735 when using ex-post revised data for all series. It can be shown that two thirds of this improvement arises from replacing preliminary price data releases by final data releases and one third of the improvement arises from replacing the nowcasts used to fill in missing data by ex-post revised data. We conclude that efforts to provide more accurate data should focus on the nominal U.S. refiners' acquisition cost for imports.

The second column of Table 5 confirms that no such efforts are required for the real WTI price for the simple reason that the nominal WTI price is already available in real time. As in the left column, there is little scope for improving the real-time forecast accuracy for the real WTI price by improved data collection for the other time series, which explains why the real-time and ex-post revised results are so similar.

\subsection{Forecast Error Diagnostics}

The results in Tables 1 and 2 summarize the average real-time forecast accuracy of AR, ARMA and VAR models. An obvious question is how sensitive these results are to the evaluation period and what is driving the superior forecast accuracy of the BVAR model in particular compared with the random walk model. For expository purposes, we focus on the 1-month ahead BVAR(24) forecast of the real U.S. refiners' acquisition cost for crude oil imports. Very similar results hold at the 3-month horizon. The upper panel of Figure 1 illustrates that much of the MSPE reduction occurred during 2008-2010, when the real price of oil fluctuated wildly. During the preceding sixteen years, the real price of oil evolved much more smoothly and the differences are less pronounced. Nevertheless, the recursive MSPE of the four-variable BVAR(24) model tends to be as low as or lower than the MSPE of the no-change forecast, which in itself is a surprising finding. A priori one would have expected the no-change forecast to have lower MSPE given its much greater parsimony.

The second panel in Figure 1 shows that by far the largest forecast errors during our evaluation period occurred during 2008. Both the no-change forecast and the BVAR(24) model underpredicted the real price of oil in early 2008 and overpredicted the real price of oil in the second half of 2008. The difference is that the BVAR(24) model got the general direction of the 
change in the real price of oil right and hence produced smaller forecast errors throughout that year. Although the gains in directional accuracy are not dramatic, the lower panel of Figure 1 illustrates that the BVAR forecast had consistently high directional accuracy throughout most of the evaluation period.

\section{Alternative Forecasting Models}

An obvious question of interest is how the forecast accuracy results in Tables 1 through 4 compare to alternative non-regression based forecasting methods. One alternative approach exploits information from oil futures markets. Central banks typically rely on the price of oil futures contracts in generating forecasts of the nominal price of oil. This forecast is then converted to a forecast for the real price of oil by subtracting expected inflation. This approach is embodied in the forecasting model

$$
R_{t+h \mid t}=R_{t}\left(1+f_{t}^{h}-s_{t}-\pi_{t}^{h}\right)
$$

where $R_{t}$ denotes the current level of the real price of oil, $f_{t}^{h}$ the log of the current oil futures price for maturity $h, s_{t}$ the corresponding WTI spot price, and $\pi_{t}^{h}$ the current level of U.S. CPI inflation over the last $h$ periods. In other words, we adopt a no-change forecast of inflation for simplicity. Undoubtedly, the inflation forecast could be refined further, but there is little loss in generality in our approach, given that fluctuations in the nominal price of oil dominate the evolution of the real price of oil. More sophisticated inflation forecasts would not be expected to change the substance of our findings. Both $f_{t}^{h}$ and $s_{t}$ are available in real time. The inflation forecast and $R_{t}$ are obtained from nowcasting methods as in section 3.1.

Table 6 shows that this method lowers the recursive MSPE for the U.S. refiners' acquisition cost at all horizons. The reductions in MSPE range from $0 \%$ to $9 \%$ with a tendency to increase with the forecasting horizon. Very similar results would be obtained using ex-post revised data. However, none of the reductions in MSPEs are statistically significant based on the Diebold and Mariano (1995) test. When forecasting the real WTI price instead, this futures-based forecasting method is even less successful. Only at horizons of 9 and 12 are there any noticeable reductions in the MSPE, and, again, none of the reductions are statistically significant. Essentially the same result holds using ex-post revised data. Both for the real refiners' 
acquisition cost and for the real WTI price, there is some evidence of significant gains in realtime directional accuracy at horizons 9 and 12. These gains are never larger than the directional accuracy gains for the BVAR(24) model, however. We conclude that despite its apparent simplicity and ease of implementation the futures-based forecasting method cannot be recommended.

Yet another non-regression-based forecasting method is to exploit real-time information from non-oil industrial commodity prices. Alquist, Kilian, and Vigfusson (2011) showed that recent percent changes in the price of industrial raw materials have significant predictive power for the nominal WTI price of oil at short horizons. This finding suggests the forecasting model

$$
R_{t+h \mid t}=R_{t}\left(1+\pi_{t}^{h \text {,industrial raw materials }}-\pi_{t}^{h}\right),
$$

where $\pi_{t}^{\text {h,industrial raw materials }}$ stands for the percent change of the CRB index of the price of industrial raw materials (other than oil) over the preceding $h$ months. This index is available in real time.

Table 6 shows that this method indeed produces large reductions in the real-time MSPE at horizons of 1 and 3 months. The reductions at horizon 3 are actually larger than those from VAR or BVAR models, but statistically significant only at the 10\% level. Like the BVAR(24) model this commodity-price based forecasting method has consistently high and often statistically significant directional accuracy with success ratios between $55 \%$ and $61 \%$ in real time. Its main disadvantage compared with the BVAR(24) model is its higher MSPE at horizons 6,9 , and 12 . The relatively favorable forecasting performance of this method is no accident. To the extent that industrial commodity prices are driven by the same fluctuations in global real economic activity as the price of oil, one would expect them to be a good proxy for one of the key predictors included in the VAR model of Kilian and Murphy (2010). For the same reason, it is no surprise that the forecast accuracy of the model based on industrial commodity prices further improves when using ex-post revised data.

One obvious limitation of forecasting models based on non-oil industrial commodity prices is that they can be expected to perform well as long as the real price of oil is driven by the global business cycle as opposed to geopolitical factors. One would not expect this model to fare well during the Libyan crisis of 2011, for example. The BVAR(24) model in contrast, allows for a richer set of predictors, and hence is likely to be more robust. 


\section{Structural Forecasting Models}

Standard forecasting models are selected to produce low MSPE forecasts or to have high directional accuracy, with little regard to the underlying economic structure. One important limitation of such forecasting methods from the point of view of many end-users is that they do not shed light on why the real price of oil has fluctuated in the recent past. An equally important limitation is that such forecasting methods do not convey how sensitive the real oil price forecasts are to hypothetical events in the global market for crude oil. Forecasts that condition on such hypothetical events can be viewed as conditional forecasts (see, e.g., Waggoner and Zha 1999). They are also known as forecast scenarios. For example, a user may be interested in how a temporary oil production shortfall would affect the forecast of the real price of oil. Similarly, one may be interested in exploring the possible consequences of civil unrest in Libya, or in exploring how much a period of unexpectedly low global demand for crude oil caused by a global recession would lower the real price of oil. The construction of such forecast scenarios requires the use of structural econometric models.

Structural models of the global market for crude oil have recently been developed by Kilian (2009), Kilian and Murphy (2010, 2011), and Baumeister and Peersman (2010), among others. In this section, we focus on the structural vector autoregressive model proposed in Kilian and Murphy (2010). This model was designed to help us distinguish, in particular, between unexpected oil production shortfalls, unexpected changes in the global demand for crude oil driven by the global business cycle, and shocks to the demand for above-ground crude oil inventories driven by speculative motives. If speculation were conducted by oil producers rather than oil consumers, with oil producers deliberately delaying the production of crude oil in anticipation of higher prices, the model by construction would treat such shocks as negative oil supply shocks. Changes in the composition of these shocks help explain why conventional regressions of macroeconomic aggregates on the price of oil tend to be unstable. They also are potentially important in interpreting oil price forecasts.

These structural oil demand and oil supply shocks are jointly identified primarily based on a combination of sign restrictions on the structural impulse responses and bounds on impact price elasticities of oil demand and oil supply. ${ }^{6}$ The model exploits the fact that the spot and

\footnotetext{
${ }^{6}$ More specifically, the identifying assumptions are that: (1) a negative oil supply shock shifts the supply curve to the left along the oil demand curve, resulting in a decrease in oil production and an increase in the price of oil, which
} 
futures markets for crude oil are linked by an arbitrage condition (see Alquist and Kilian 2010). Thus, any speculation taking place in the oil futures market implies a shift in inventory demand in the spot market by construction. This fact allows us to abstract from the oil futures market altogether. Indeed, it can be shown that the structural shocks identified by this model are fundamental in that the oil futures spread does not Granger-cause the other variables included in the model (see Giannone and Reichlin 2006).

The reduced-form representation of the Kilian and Murphy (2010) model corresponds to the four-variable VAR model we already considered in sections 2 and 3 and showed to be quite accurate compared with the no-change benchmark as well as competing models. Conditional forecasts may be constructed from the structural moving average representation of the VAR model also used for the historical decomposition by feeding in sequences of future oil demand and oil supply shocks corresponding to pre-specified events. Such events may be purely hypothetical or may be motivated based on sequences of past structural shocks. In practice, we normalize all conditional forecasts relative to the baseline forecast from the structural model obtained by setting all future structural shocks to zero. Thus, the plot of the normalized conditional forecast may be interpreted as the upward or downward adjustments of the baseline forecast that would be required if a given hypothetical scenario were to occur. This approach allows the forecaster to explore various risks inherent in the forecast of the real price of oil and to convey the consequences to the end-user. In fact, these forecast scenarios could be readily interpreted in conjunction with any baseline forecast, be it a reduced-form VAR forecast or a nochange forecast, for example.

In conjunction with historical decompositions, this approach satisfies the needs of central bankers and of other end-users not only for accurate forecasts, but for an economic interpretation of both historical oil price data and oil price forecasts. An important difference to unconditional forecasting methods is that in generating conditional forecasts the objective is to identify to the best of our ability the true dynamic effects of structural shocks, which necessitates the use of expost revised data. Accordingly, all of the analysis in this section is based on ex-post revised data.

causes real activity to decline; (2) a positive demand shock is associated with an unexpected increase in global real activity which shifts the oil demand curve upward leading to a quantity and price increase; (3) a positive speculative demand shock reflecting expectations of a tightening oil market is associated with an increase in oil inventories and in the real price of oil which stimulates oil production but exerts a negative effect on real economic activity. In addition to these sign restrictions, we impose that the impact price elasticity of oil supply is bounded above ( $\leq$ 0.025 ) and that the impact price elasticity of oil demand is restricted to be negative and smaller than the long-run price elasticity of -0.8 . 
The proposed approach allows the forecaster to complement the baseline real-time forecast by a coherent economic story as well as a formal analysis of the risks involved in this forecast. In section 5.2, we illustrate this approach for eight hypothetical scenarios. We begin in section 5.1 with a brief structural analysis of the sources of fluctuations in the real price of oil since the late 1970s and especially in recent years.

\subsection{Historical Decompositions}

Our analysis updates that in Kilian and Murphy (2010) from 2009.8 until 2010.6, the last date for which we have available ex-post revised data. Although the model is only set-identified, all admissible models can be shown to be quite similar, allowing us to focus on one such model with little loss of generality. In the analysis below, we follow Kilian and Murphy in selecting the model with a price elasticity of oil demand closest to the posterior median of that elasticity. The structural moving average representation of this model allows us to decompose fluctuations in the real price of oil into orthogonal components corresponding to different structural shocks.

Each panel in Figure 2 plots the cumulative effect on the real price of oil of one structural shock, while turning off all other shocks. The sum of these three components represents the combined cumulative effect of all three shocks on the real price of oil. This historical decomposition allows us to understand the relative contribution of each oil demand and oil supply shock during key historical episodes. The vertical bars correspond to key events in the global oil market including the Iranian Revolution in late 1978, the outbreak of the Iran-Iraq War in late 1980, the collapse of OPEC at the end of 1985, the August 1990 invasion of Kuwait, the Asian crisis of 1997, the Venezuelan oil supply shock of late 2002 (immediately followed by the Iraq War of early 2003), and the global financial crisis of mid-2008.

Each historical episode is characterized by a different mix of structural shocks. For example, the 1979 surge in the real price of oil was jointly caused by strong unexpected flow demand, associated with a boom in the world economy and in industrial commodity markets, and by a surge in speculative demand starting in May 1979 (with little contribution from the unanticipated oil supply disruptions associated with the Iranian Revolution earlier that year). In contrast, the decline in the real price of oil in 1998, for example, can be attributed primarily to an unexpected decline in flow demand for crude oil following the Asian crisis. 
These and other episodes have already been discussed in Kilian and Murphy (2010). Our focus in this paper is on the additional evidence for the aftermath of the financial crisis. Figure 2 illustrates that much of the surge in the real price of oil between 2003 and mid-2008 was caused by repeated unexpected increases in the global business cycle as opposed to positive speculative demand shocks or negative oil supply shocks. This finding is also consistent with independent evidence on revisions to professional real-GDP growth forecasts for the largest economies in Kilian and Hicks (2010). Kilian and Hicks documented that these forecast surprises were associated with unexpected growth in emerging Asia.

As financial markets collapsed in the second half of 2008, so did global real activity and hence demand for industrial commodities such as crude oil. The collapse in global demand far exceeded the corresponding decline in real GDP and industrial production because global shipping of industrial commodities was effectively suspended, as policymakers scrambled to restore financial markets. In early 2009, global demand recovered as quickly as it had collapsed, when confidence was restored. The cumulative effect of flow demand shocks reached a peak in January of 2010 that is only somewhat lower than the all-time high of mid-2008. In the first half of 2010 these demand pressures eased, however, and the cumulative effect of flow demand shocks on the real price of oil receded to levels similar to 2007.

In contrast, flow supply shocks and speculative demands shock did not play a decisive role during 2003-10. This finding is particularly informative given that the same model assigns an important role to speculative demand shocks during 1979, 1986, and 1990/91. These findings indicate that the model indeed has the ability to detect speculation when it exists. Although the structural model cannot distinguish between desirable and undesirable speculation, that distinction does not matter from a policy point of view, given that there is no evidence at all in the model of speculation being responsible for the recent volatility in the real price of oil, which by construction also rules out the hypothesis that undesirable speculation by financial market participants caused these oil price fluctuations.

\subsection{Forecast Scenarios}

An obvious question is how sensitive standard reduced-form forecasts are to a variety of forecast scenarios of policy interest. There is a strict correspondence between standard reduced-form VAR forecasts and forecasts from the structural moving-average representation. The reduced- 
form forecast or baseline forecast corresponds to the expected change in the real price of oil conditional on all future shocks being zero in expectation. Departures from this benchmark can be constructed by feeding pre-specified sequences of future structural shocks into the structural moving-average representation and extrapolating the data. A forecast scenario is defined as a sequence of future structural shocks. The implied movements in the real price of oil relative to the baseline forecast (obtained by setting all future structural shocks to zero) correspond to the revision of the reduced-form forecast implied by this scenario.

In constructing forecast scenarios from structural VAR models we are interested in our best guess of the effect of a hypothetical sequence of future structural shocks on the forecast of the real price of oil. This means that forecast scenarios (much like structural impulse responses) must be constructed from ex-post revised data rather than real-time data. The departures from the baseline VAR forecast implied by a given forecast scenario are time invariant. In other words, a given hypothetical sequence of shocks will cause the same revisions of the baseline forecast at each point in time.

Figure 3 considers five specific scenarios. The forecast horizon in all cases is set to 24 months for illustrative purposes. The first scenario involves an unexpected return of Iraqi oil production to its pre-war level. Prior to the invasion of Kuwait in August of 1990, Iraq produced 3.454 millions of barrels per day (mbd). Today, Iraqi production has stabilized at $2.625 \mathrm{mbd}$. An obvious question of interest to market participants is how much further efforts at increasing Iraqi oil production are likely to relieve upward pressures on the real price of oil. Although there is reason to believe that neglect may have reduced Iraqi capacity compared with 1990, a useful benchmark is a scenario of an increase in global crude oil production growth corresponding to $0.829 \mathrm{mbd}$. This corresponds to an increase in global crude oil production of $1.1 \%$, which is well within the variation of historical data. We simulate the effects of such a stimulus by calibrating a one-time structural oil supply shock such that the impact response of global oil production growth in the first forecast period is $1.1 \%$. All other future structural shocks are set to zero. Figure 3 shows that the resulting reduction in the real price of oil expressed in percent relative to the baseline forecast is modest. The real price of oil would temporarily decline by about $5 \%$.

The second scenario involves shutting down Libyan oil production, motivated by events in Libya since February of 2011. This event translates to a negative flow supply shock corresponding to a $2.2 \%$ decline in global crude oil production on impact. The real price of oil 
temporarily increases by as much as 7\% relative to the baseline forecast. This example illustrates that the sustained increase in the real price of oil since February 2011 cannot be attributed to the oil supply disruption alone. Indeed, the model allows for another important channel by which geopolitical events in the Middle East may affect the real price of oil and that channel is speculative demand. As political unrest and civil strife in Egypt, Oman, Yemen, Bahrain, Libya and Syria grows, it is only natural for oil market participants to grow concerned about the political stability of major oil suppliers such as Saudi Arabia, resulting in increased demand for oil inventories and hence a higher real price of oil. As this shift in speculative demand is driven by fears of contagion of political unrest or war, we refer to this situation as a contagion scenario. In principle such fears could be arbitrarily weak or strong, making it difficult to assess the quantitative importance of this channel, but the historical experience of earlier episodes in Figure 2 provides some guidance.

One contagion scenario can be motivated by focusing on the surge in speculative demand that occurred preceding and following the invasion of Kuwait in August of 1990. As discussed in Kilian (2008) and Kilian and Murphy (2010), among others, the invasion not only caused oil production in Kuwait and Iraq to cease, but raised concerns that Saudi Arabia and its smaller neighbors would be invaded next, causing a surge in speculative demand that only subsided after the U.S. had moved troops in sufficient strength to Saudi Arabia to forestall a second invasion, at which point the real price of oil declined sharply. This event provides a blueprint for a dramatic, but temporary surge in speculative demand and in the real price of oil. Figure 3 shows that when feeding in the sequence of speculative demand shocks for March 1990 through March 1991, the real price of oil rises $19 \%$ above its baseline forecast, but that dramatic increase is followed by a decline to $11 \%$ below the baseline forecast after 15 months, as crude oil inventories are liquidated after the conclusion of the crisis.

An alternative contagion scenario is the possibility of a more sustained speculative frenzy such as occurred starting in mid-1979 after the Iranian Revolution, amidst continued strong global growth. The hostage crisis in Iran led to increasing tension in the Middle East, even after Iranian oil production had resumed. There was a real possibility of a military conflict between Iran and the United States as well as concern that Iran would move against its oil-producing neighbors in the Persian Gulf. The geopolitical risk was further heightened by the Soviet invasion of Afghanistan later in 1979. These events in conjunction with a booming world 
economy caused sustained increases in inventory demand and in the real price of oil between May and December of 1979 (see Figure 2). Unlike in the Gulf War scenario, there were no indications that the tension would be resolved soon. This second contagion scenario involves feeding into the model future structural shocks corresponding to the sequence of speculative demand shocks that occurred between 1979.1 and 1980.2 and were an important contributor to the 1979/80 surge in the real price of oil (see Figure 2). Figure 3 shows that an event such as this would raise the baseline forecast temporarily by as much as $22 \%$ after 15 months.

The last panel of Figure 3 considers a scenario that combines the Libyan production shortfall with a contagion scenario built on the 1990/91 contagion scenario. The model predicts an overall increase in the real price of oil of about 23\%. Considering that the refiners' acquisition cost for crude oil imports stood at 88 dollars in January of 2011, this would have implied an increase to $\$ 104$ by May 2011, with the expectation that the real price might rise as high as $\$ 108$ dollars by July if the 1990/91 episode is any guide. Although actual shifts in inventory demand may be higher or lower than this historical precedent, our analysis provides at least a benchmark for thinking about the potential effects of such geopolitical events. In this case, the nominal WTI price of oil had increased to $\$ 114$ by the end of April 2011 already, consistent with even stronger speculative demand pressures, especially considering the slowdown in global real activity in early 2011.

Whereas the scenarios in Figure 3 hypothesize future changes in oil production and/or in speculative demand, an alternative thought experiment involves a recovery of the flow demand for oil and other industrial commodities. Although the historical decomposition in Figure 2 indicates a substantial recovery since the trough of the Great Recession, consistent with renewed robust growth in emerging Asia, this recovery has not been complete. By 2010.6, the cumulative effect of flow demand shocks on the real price of oil was at about the same level as in September 2007. The global recovery scenario considered in the upper panel of Figure 4 asks how an unexpected surge in the demand for oil similar to that occurring during 2007.9-2008.6 would affect the real price of oil. This scenario involves feeding into the structural moving-average representation future flow demand shocks corresponding to the sequence of global flow demand shocks that occurred in 2007.9-2008.6, while setting all other future structural shocks equal to their expected value of zero. Figure 4 shows a persistent hump-shaped increase in the real price of oil reaching a peak after a year and a half. The predicted real price of oil may exceed the 
baseline forecast by up to $50 \%$, underscoring the sensitivity of the real price of oil to global business cycle fluctuations.

We conclude with two nightmare scenarios which combine the global recovery scenario with the Libyan supply shock scenario and one of the contagion scenarios. The revisions in the baseline forecast depend primarily on how the contagion is modeled. The first nightmare scenario in the lower panel of Figure 4 focuses on a gradual and sustained increase in speculative demand, as occurred in 1979. The second nightmare scenario is based on a more abrupt, but shorter-lived episode of speculative demand pressures, as occurred between March 1990 and March 1991. The first scenario implies a dramatic upward adjustment by near 58\% in the real price of oil after eight months, followed by a decline to levels about 30\%-34\% in excess of the baseline forecast after 15 months. To put these results in perspective, suppose that we are generating a forecast as of January 2011 (right before the Libyan crisis), when the price of oil was $\$ 88$. Taking the no-change forecast as the benchmark, Figure 4 predicts a surge in the real price of oil to $\$ 174$ by August 2011, followed by a decline to between $\$ 143$ and $\$ 148$ (all in January 2011 prices) by the end of 2012.

The second scenario is associated with a more gradual, but sustained increase in the real price of oil relative to the baseline forecast. The peak increase is $68 \%$ above the baseline forecast after about a year, followed by a more gradual decline to $54 \%$ above the baseline forecast. To put this scenario in perspective, again consider a no-change forecast of the real price of oil as of January 2011 as the baseline. Figure 4 implies that the real price of oil would be expected to peak at \$185 (in January 2011 prices) in early 2012 before declining to $\$ 169$ by the end of 2012 . Clearly such forecast scenarios are low probability events, but it is precisely risk analysis along such lines that is needed in policy analysis.

\subsection{The Baseline Real-Time Forecast}

Having computed historical decompositions and forecast scenarios based on the ex-post revised data available until 2010.6, a forecaster would proceed by constructing a real-time baseline forecast using data up to 2010.12, which is the last period for which real-time data were available 
as of the time this paper was written. As in section 3, we use nowcasting to fill any gaps in the most recent vintage. ${ }^{7}$

Figure 5a shows a number of real-time baseline forecasts as of 2010.12, including the nochange forecast, the forecast from the Kilian-Murphy (2010) structural VAR model, and the forecast based on oil futures prices. All forecasts are expressed in real 2010.12 dollars. Based on nowcasting, the observed real price of oil in 2010.12 is \$97. Figure 5a illustrates that these three real-time forecasts indeed can be substantially different. For example, the VAR forecast indicates an initial increase in the real price of oil to \$105 after one quarter, followed by decline to between $\$ 75$ and $\$ 83$ in the second year. The futures-based forecast indicates a gradual decline from $\$ 97$ to $\$ 90$ after two years. The no-change forecast differs from both of these forecasts. Based on the evidence we presented in sections 3 and 4, the VAR real-time forecast is likely to be the most reliable forecast overall in terms of MSPE and directional accuracy among these three forecasts, at least in the short run.

Figure 5b focuses on the baseline forecast implied by the Kilian-Murphy (2010) model and the full range of alternative forecast scenarios discussed in section 5.2. In practice, these alternative forecasts could be combined, if one were willing to attach probability weights to each scenario. For our purposes, the focus is on illustrating how sensitive the baseline forecast is to alternative assumptions about future demand and supply conditions in the global market for crude oil. Figure 5b illustrates that the real price of oil may rise as high as \$148 after one quarter or fall as low as $\$ 100$. After one year, the range is between $\$ 76$ and $\$ 131$; at the two-year horizon between $\$ 66$ and $\$ 115$.

These results, while necessarily tentative, illustrate how structural models of oil markets may be used to assess risks in oil price forecasts and to investigate the sensitivity of reducedform forecasts to specific economic events. Conditional projections, of course, are only as good as the underlying structural models. Our example highlights the importance of refining these models and of improving structural forecasting methods, perhaps in conjunction with Bayesian methods of estimating VAR forecasting models. Clearly, forecast scenarios could alternatively be constructed from DSGE models, provided that these models incorporate suitable structural oil market models. One reason for focusing on the model in Kilian and Murphy (2010) instead is

\footnotetext{
${ }^{7}$ Note that this sample period does not include the period of Libyan unrest and turmoil in oil markets that started in February 2011.
} 
that currently available DSGE models are still rather simplistic when it comes to modeling the global oil market to be useful for policy analysis. In particular, modeling the global demand for industrial commodities (as opposed to measures of value added or productivity) has proved challenging. As these DSGE models become more sophisticated, one would expect this situation to change, however. Whether the additional model structure required in specifying a DSGE model compared with a structural VAR model on balance will help improve out-of-sample forecast accuracy remains an open question. Our focus in this paper is on illustrating the use of structural models in constructing forecast scenarios rather than on advocating one type of structural model over another.

\section{Conclusion}

The importance of real-time forecasting is well recognized in the literature (see, e.g., Croushore 2011). Much of the work on real-time forecasting to date has focused on domestic macroeconomic aggregates. In contrast, our focus in this paper has been on generating real-time forecasts for the real price of oil, which is widely considered one of the key global macroeconomic indicators. Work on the relative performance of alternative real-time forecasting methods for the real price of oil has been conspicuously absent from the literature. Using a newly constructed real-time data set, we provided strong evidence that for horizons up to one year, it is possible to forecast more accurately than the no-change forecast in real time. This result is in striking contrast to the literature on forecasting asset prices. We showed that much of the empirical evidence against the no-change forecast comes from 2008-10, when the real price of oil fluctuated wildly. In the preceding sixteen years, the real price of oil evolved more smoothly and the MSPE reductions were much more modest. At longer horizons, the ability of these models to improve on the random walk model quickly dissipates, regardless of whether one is using real-time or ex-post revised data. This finding is robust to whether the real price of oil is defined in terms of the U.S. refiners' acquisition cost for crude oil imports or the WTI price.

Our forecast accuracy comparison included forecasts from various AR, ARMA, and VAR models, forecasts based on oil futures price spreads, and forecasts based on recent price changes in non-oil industrial commodity prices. We concluded that recently proposed VAR models of the global oil market produce the most accurate short-run forecasts. Forecasts from BVAR(24) models offer the best overall combination of low MSPEs and high directional 
accuracy. ARMA models are not as accurate in the short run as VAR models and lack directional accuracy, but may produce larger MSPE reductions at horizons of 6, 9, and 12 months.

Users of forecasts of the real price of oil such as central banks are interested not only in accurate out-of-sample forecasts, however, but in understanding the past, current, and future evolution of the real price of oil. Of particular importance is the ability to quantify the forecast risks associated with a baseline point forecast. We illustrated how both of these objectives may be attained based on the same type of VAR model that was shown to perform well in out-ofsample forecasting. Under suitable additional identifying assumptions, this model may be used not only to interpret past and current fluctuations in the real oil price data in light of economic models, but to evaluate the sensitivity of the baseline forecast to alternative forecast scenarios. We showed how such conditional forecasts may be generated from the structural movingaverage representation of the VAR model. On the basis of data until 2010.12, we showed that an unexpected recovery of the world economy, for example, is expected to raise the real price of oil by an additional 50 percent after a year and a half. On the other hand, a surge in speculative demand driven by civil unrest in the Middle East would increase the real price of oil by $20 \%$ after about one year, if the shift in inventory demand is comparable to that during the Iranian crisis of 1979. 


\section{References}

Alquist, R., and L. Kilian (2010), "What Do We Learn from the Price of Crude Oil Futures?” Journal of Applied Econometrics, 25, 539-573.

Alquist, R., Kilian, L., and R.J. Vigfusson (2011), “Forecasting the Price of Oil,” prepared for: G. Elliott and A. Timmermann (eds.), Handbook of Economic Forecasting, 2, Amsterdam: North-Holland.

Baumeister, C., and G. Peersman (2010), "Sources of the Volatility Puzzle in the Crude Oil Market,” mimeo, Department of Economics, Ghent University.

Carlton, A.B. (2010), “Oil Prices and Real-Time Output Growth,” mimeo, Department of Economics, University of Houston.

Clark, T.E., and M. McCracken (2009), "Tests of Equal Predictive Ability with Real-Time Data," Journal of Business and Economic Statistics, 27, 441-454.

Clements, M.P., and A.B. Galvão (2010), "Real-Time Forecasting of Inflation and Output Growth in the Presence of Data Revisions,” mimeo, Department of Economics, Queen Mary University of London.

Croushore, D. (2006), “Forecasting with Real-Time Macroeconomic Data,” in: G. Elliott, C.W.J. Granger and A. Timmermann (eds.), Handbook of Economic Forecasting, Amsterdam: North-Holland, 961-982.

Croushore, D. (2011), “Frontiers of Real-Time Data Analysis,” Journal of Economic Literature, 49, $72-100$.

De Jong, P. (1987),”Rational Economic Data Revisions,” Journal of Business and Economic Statistics, 5, 539-548.

Diebold, F.X., and R.S. Mariano (1995), “Comparing Predictive Accuracy,” Journal of Business and Economic Statistics, 13, 253-263.

Faust, J., Rogers, J., and J.H. Wright (2003), “Exchange Rate Forecasting: The Errors We've Really Made,” Journal of International Economics, 60, 35-59.

Faust, J., Rogers, J., and J.H. Wright (2005), “News and Noise in G-7 GDP Announcements," Journal of Money, Credit, and Banking, 37, 403-419.

Giannone, D., Lenza, M. and G. Primiceri (2010), "Prior Selection for Vector Autoregressions,” mimeo, Department of Economics, Free University of Brussels.

Giannone, D., and L. Reichlin (2006), "Does Information Help Recover Structural Shocks from Past Observations," Journal of the European Economic Association, 4, 455-465. 
Kilian, L. (2008), "Exogenous Oil Supply Shocks: How Big Are They and How Much Do They Matter for the U.S. Economy?” Review of Economics and Statistics, 90, 216-240.

Kilian, L. (2009), "Not All Oil Price Shocks Are Alike: Disentangling Demand and Supply Shocks in the Crude Oil Market," American Economic Review, 99, 1053-1069.

Kilian, L., and B. Hicks (2010), "Did Unexpectedly Strong Economic Growth Cause the Oil Price Shock of 2003-2008?” mimeo, Department of Economics, University of Michigan.

Kilian, L., and D. Murphy (2010), "The Role of Inventories and Speculative Trading in the Global Market for Crude Oil,” mimeo, University of Michigan.

Kilian, L., and D. Murphy (2011), "Why Agnostic Sign Restrictions Are Not Enough: Understanding the Dynamics of Oil Market VAR Models," forthcoming: Journal of the European Economic Association.

Kilian, L., and C. Vega (2011), "Do Energy Prices Respond to U.S. Macroeconomic News? A Test of the Hypothesis of Predetermined Energy Prices," Review of Economics and Statistics, 93, 660-671.

Koenig, E.F., Dolmas, S., and J. Piger (2003), "The Use and Abuse of Real-Time Data in Economic Forecasting,” Review of Economics and Statistics, 85, 618-628.

Mork, K.A. (1989), "Oil and the Macroeconomy. When Prices Go Up and Down: An Extension of Hamilton’s Results,” Journal of Political Economy, 97, 740-744.

Pesaran, M.H., and A. Timmermann (1995), "Predictability of Stock Returns: Robustness and Economic Significance,” Journal of Finance, 50, 1201-1228.

Pesaran, M.H., and A. Timmermann (2009), "Testing Dependence Among Serially Correlated Multicategory Variables,” Journal of the American Statistical Association, 104, 325337.

Ravazzolo, F., and P. Rothman (2010), “Oil and U.S. GDP: A Real-Time Out-of-Sample Examination,” mimeo, Norges Bank.

Waggoner, D.F., and T. Zha (1999), "Conditional Forecasts in Dynamic Multivariate Models," Review of Economics and Statistics, 81, 639-651. 


\section{Exhibit 1: Descriptive Statistics on Data Revisions}

(a) U.S. Refiners' Acquisition Cost of Crude Oil Imports
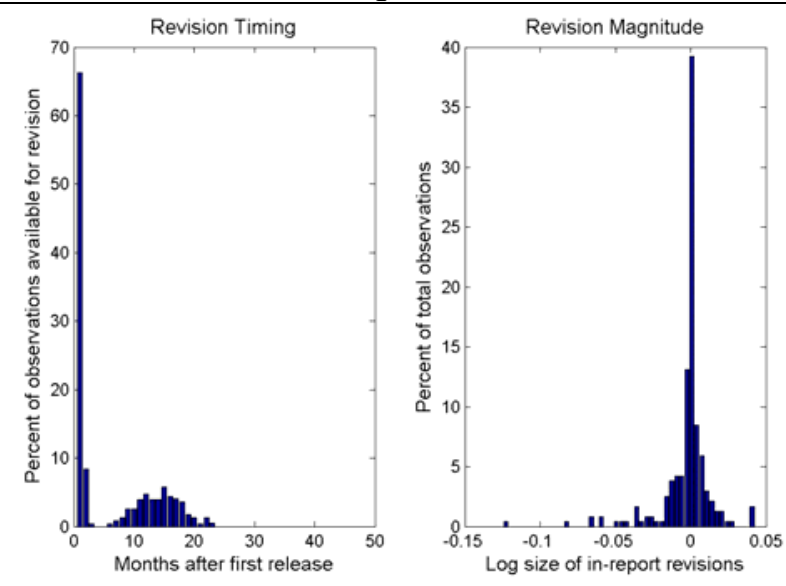

\begin{tabular}{|l|l|l|} 
& Mean & $\begin{array}{l}\text { Std. Dev. } \\
\text { relative to ex- } \\
\text { post data }\end{array}$ \\
\hline $\begin{array}{l}\text { In-report } \\
\text { revision }\end{array}$ & $-2.90 \times 10^{-3}$ & $0.733 \times 10^{-3}$ \\
\hline $\begin{array}{l}\text { Post-report } \\
\text { revision }\end{array}$ & 0 & 0 \\
\hline $\begin{array}{l}\text { Number of } \\
\text { observations }\end{array}$ & $237(1990.10-2010.06)$ \\
\hline $\begin{array}{l}\text { Vintage t reports } \\
\text { observation up to }\end{array}$ & $1991.01-2005.07: \mathrm{t}-3$ \\
\hline $\begin{array}{l}\text { Average number } \\
\text { of revisions }\end{array}$ & 1.21 \\
\hline
\end{tabular}

(b) World Crude Oil Production
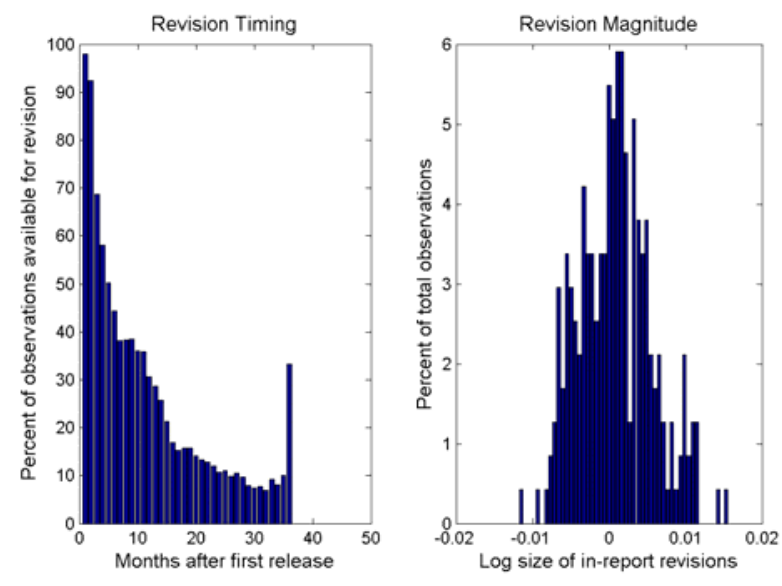

\begin{tabular}{|l|l|l|} 
& Mean & $\begin{array}{l}\text { Std. Dev. } \\
\text { relative to ex- } \\
\text { post data }\end{array}$ \\
\hline $\begin{array}{l}\text { In-report } \\
\text { revision }\end{array}$ & $-0.86 \times 10^{-3}$ & $0.976 \times 10^{-3}$ \\
\hline $\begin{array}{l}\text { Post-report } \\
\text { revision }\end{array}$ & $-0.41 \times 10^{-3}$ & $0.729 \times 10^{-3}$ \\
\hline $\begin{array}{l}\text { Number of } \\
\text { observations }\end{array}$ & $237(1990.10-2010.06)$ \\
\hline $\begin{array}{l}\text { Vintage t reports } \\
\text { observation up to }\end{array}$ & $\mathrm{t}-3$ \\
\hline $\begin{array}{l}\text { Average number } \\
\text { of revisions }\end{array}$ & 8.59 \\
\hline
\end{tabular}

(c) U.S. Crude Oil Inventories
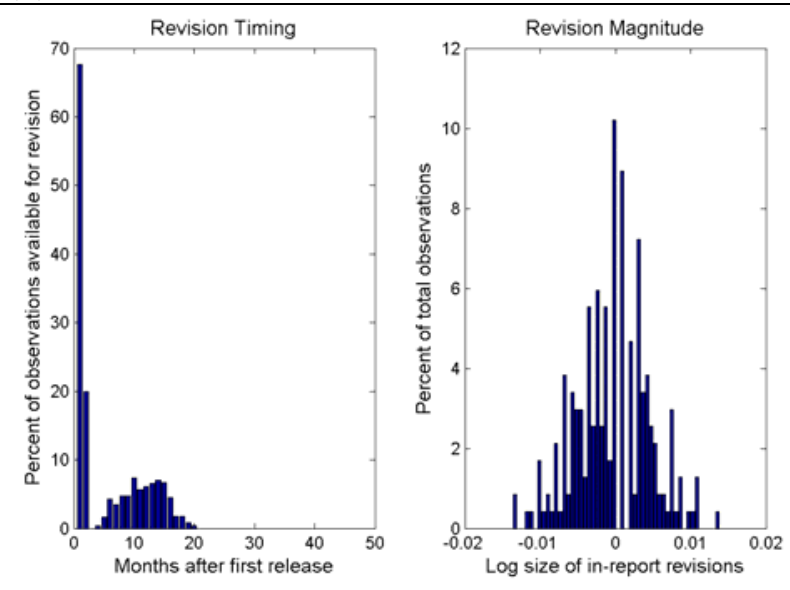

\begin{tabular}{|l|l|l|}
\hline & Mean & $\begin{array}{l}\text { Std. Dev. } \\
\text { relative to ex- } \\
\text { post data }\end{array}$ \\
\hline $\begin{array}{l}\text { In-report } \\
\text { revision }\end{array}$ & $-0.33 \times 10^{-3}$ & $0.074 \times 10^{-3}$ \\
\hline $\begin{array}{l}\text { Post-report } \\
\text { revision }\end{array}$ & $-0.02 \times 10^{-3}$ & $0.019 \times 10^{-3}$ \\
\hline $\begin{array}{l}\text { Number of } \\
\text { observations }\end{array}$ & $235(1990.12-2010.06)$ \\
\hline $\begin{array}{l}\text { Vintage t reports } \\
\text { observation up to }\end{array}$ & $\mathrm{t}-1$ \\
\hline $\begin{array}{l}\text { Average number } \\
\text { of revisions }\end{array}$ & 1.54 \\
\hline
\end{tabular}


(d) U.S. Petroleum Inventories

\begin{tabular}{|l|l|l|l|l|l|}
\hline \multicolumn{2}{|c|}{ Revision Timing } & & Mean & $\begin{array}{l}\text { Std. Dev. } \\
\text { relative to ex- } \\
\text { post data }\end{array}$ \\
\hline
\end{tabular}

(e) OECD Petroleum Inventories

\begin{tabular}{|l|l|l|l|l|l|}
\hline \multicolumn{2}{|c|}{ Revision Timing } & & Mean & $\begin{array}{l}\text { Std. Dev. } \\
\text { relative to ex- } \\
\text { post data }\end{array}$ \\
\hline
\end{tabular}

(f) U.S. CPI

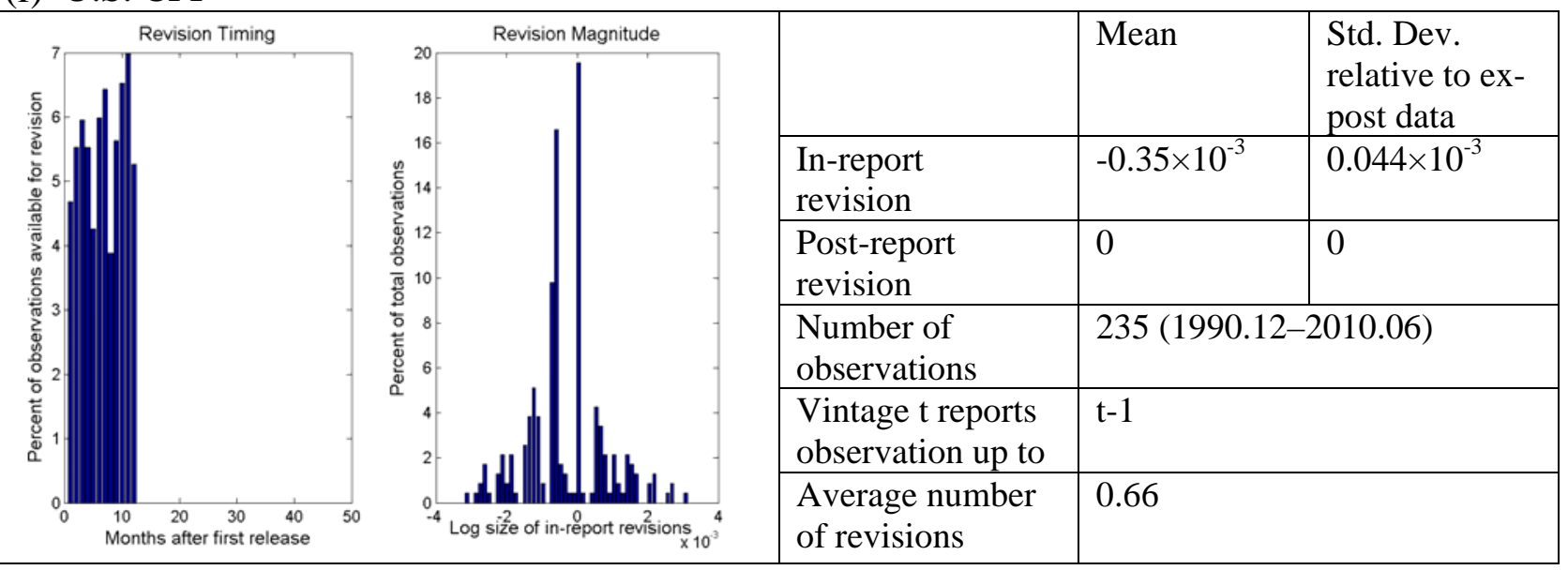


Figure 1: 1-Month Ahead Real-Time Forecast Error Diagnostics for BVAR(24) Model

U.S. Refiners' Acquisition Costs for Imports

Recursive Mean Squared Real-Time Forecast Errors

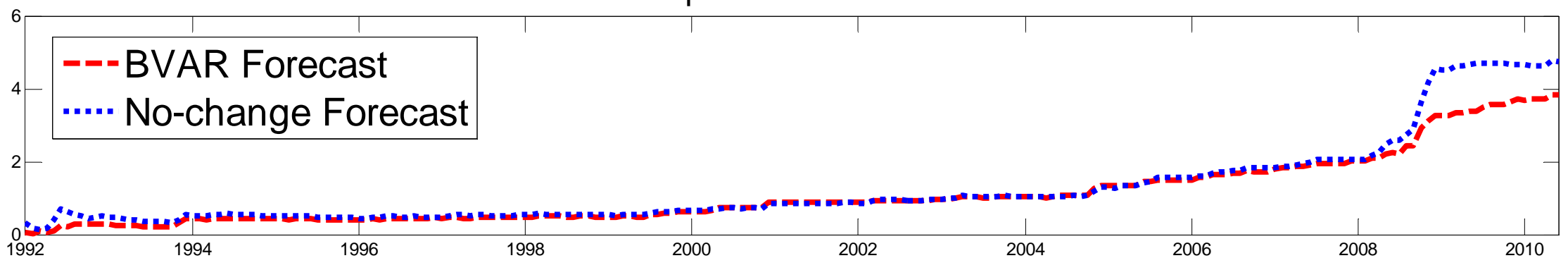

Degree of Overprediction and Underprediction

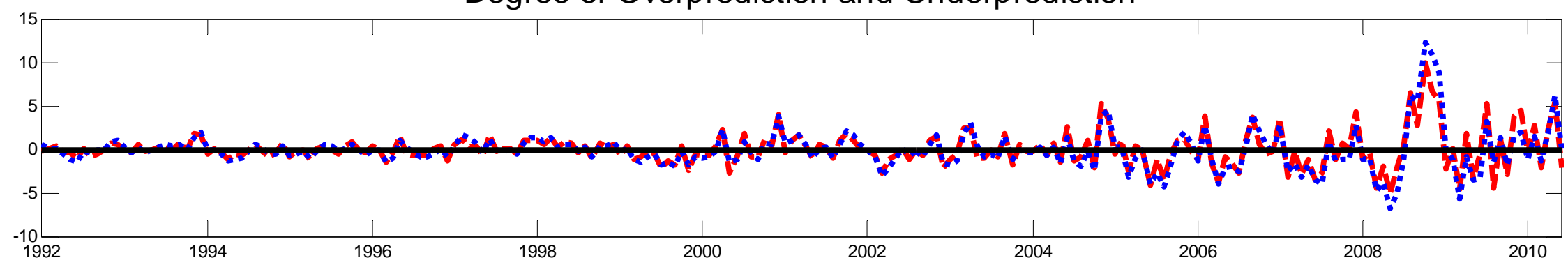

Directional Accuracy of Real-Time BVAR Forecast

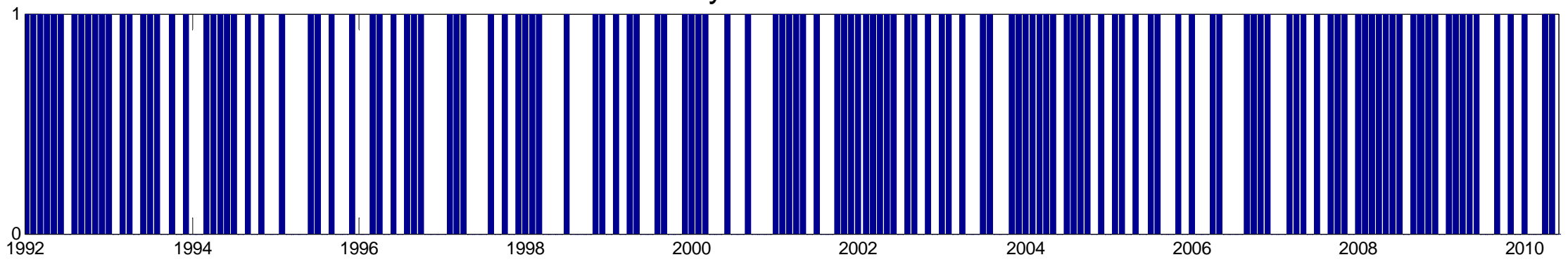

NOTES: Shaded areas in the last panel denote periods in which the model correctly forecast the sign of the change in the real oil price. 
Figure 2: Historical Decomposition for Real Refiners’ Acquisition Cost from Structural BVAR(24) Model

Cumulative Effect of Flow Supply Shock on Real Price of Crude Oil

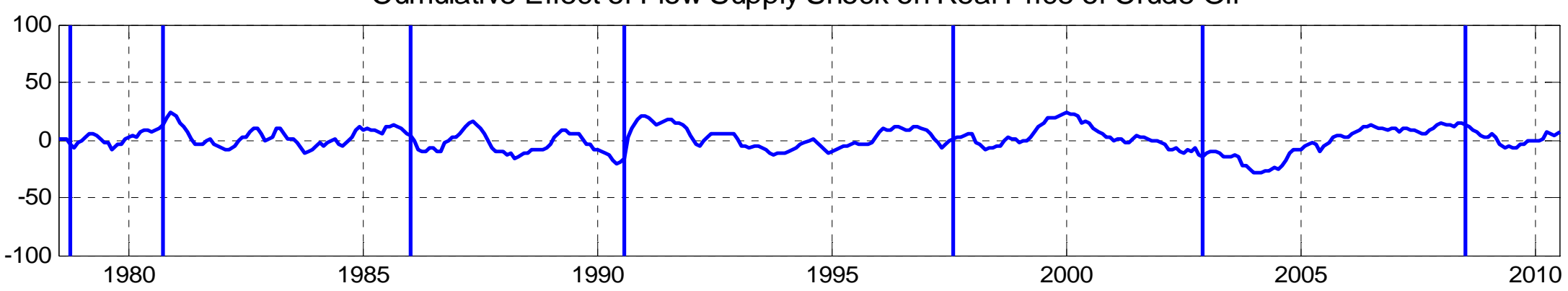

Cumulative Effect of Flow Demand Shock on Real Price of Crude Oil

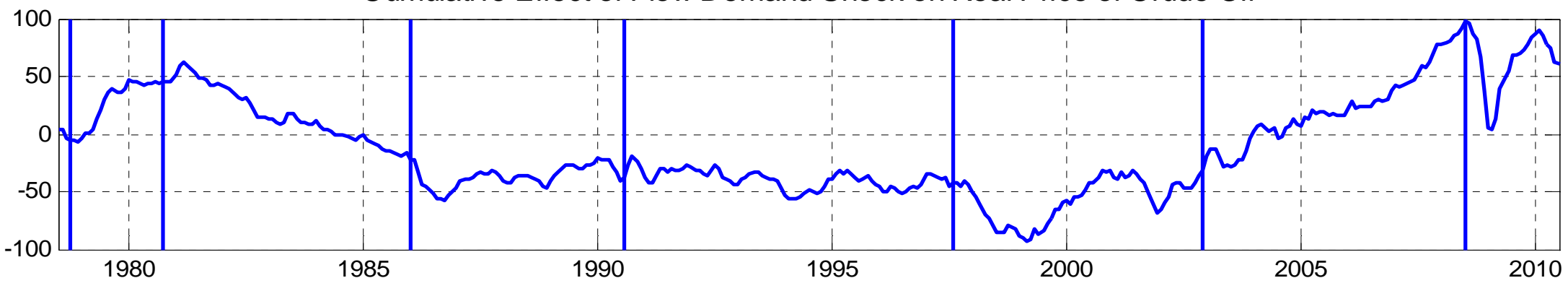

Cumulative Effect of Speculative Demand Shock on Real Price of Crude Oil

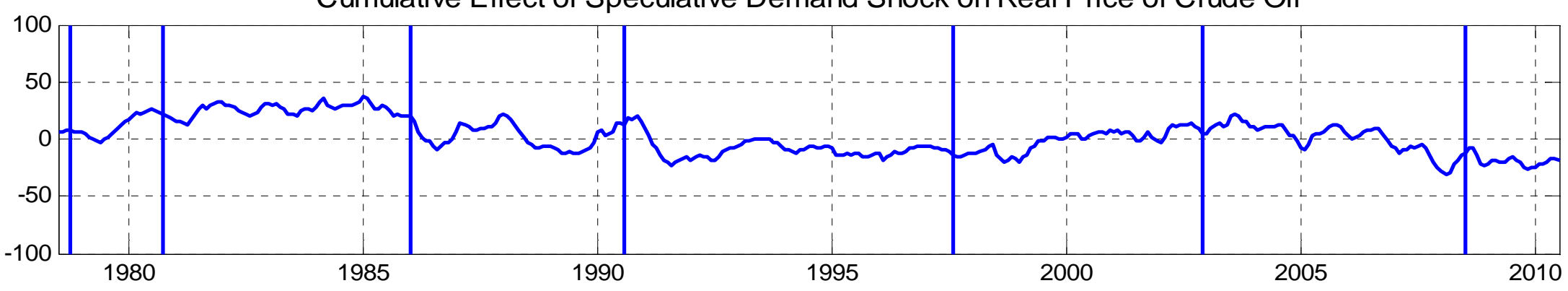

NOTES: The vertical bars correspond to key events in the global market for crude oil including the Iranian Revolution in late 1978, the outbreak of the Iran-Iraq War in late 1980, the collapse of OPEC at the end of 1985, the August 1990 invasion of Kuwait, the Asian crisis of 1997, the Venezuelan oil supply shock of late 2002 (immediately followed by the Iraq War of early 2003), and the global financial crisis of mid-2008. 
Figure 3: Forecast Scenarios for Real Refiners' Acquisition Cost

Percent Deviations from Baseline Forecast
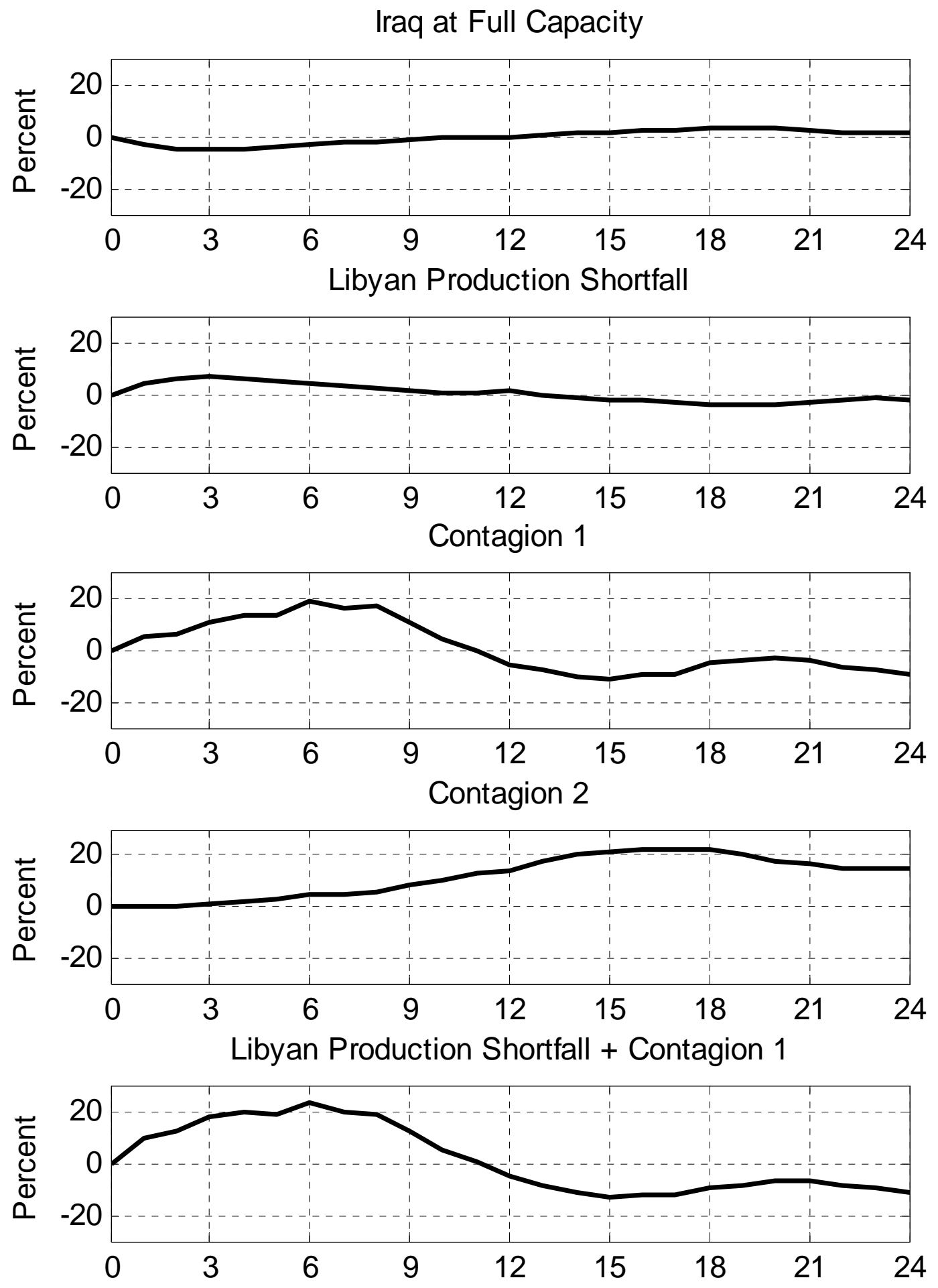

NOTES: A description of each scenario can be found in section 5. 
Figure 4: Forecast Scenarios for Real Refiners’ Acquisition Cost

Percent Deviations from Baseline Forecast
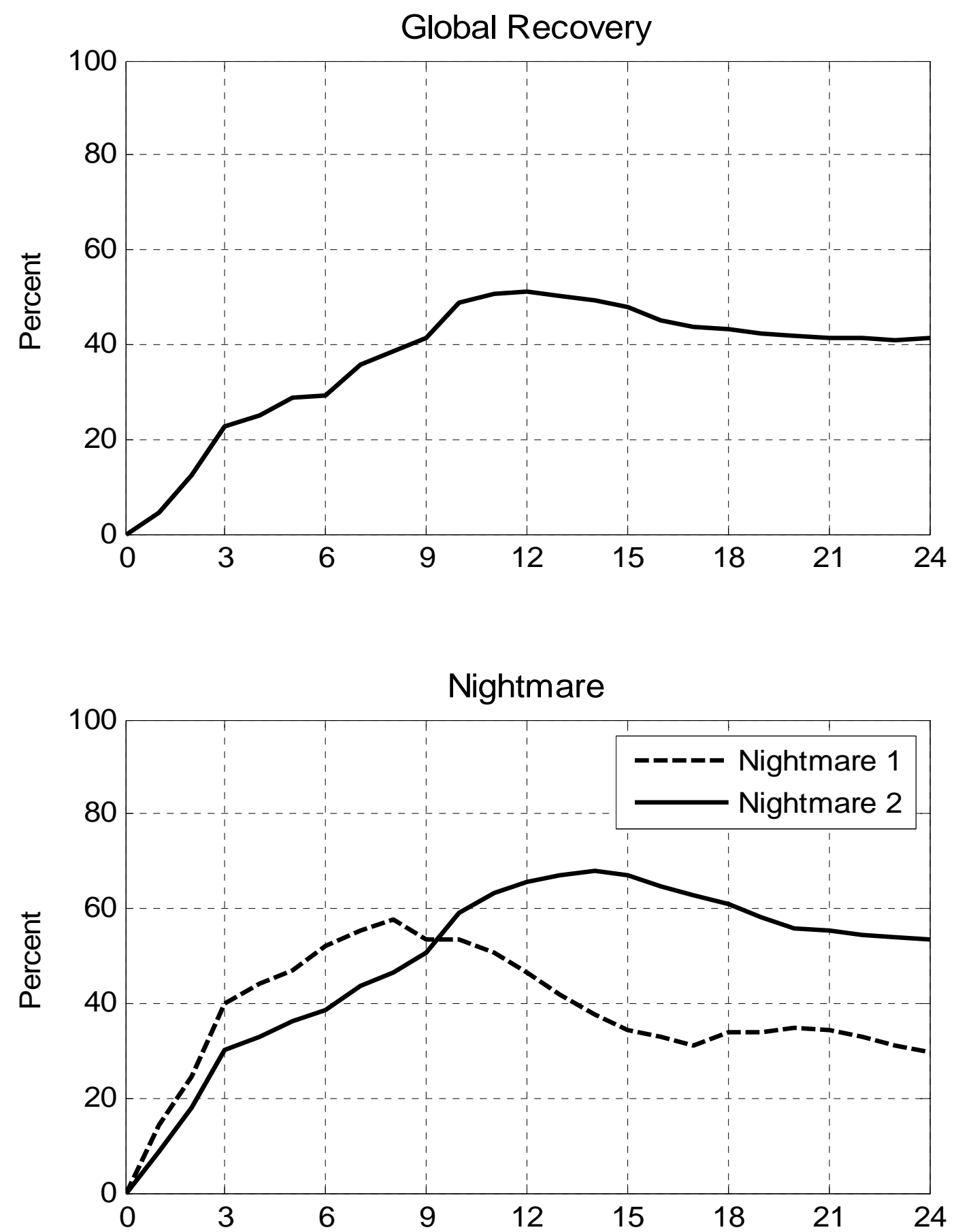

NOTES: The two nightmare scenarios combine the global recovery scenario with the Libyan production shortfall scenario and with the contagion 1 and contagion 2 scenarios, respectively. 
Figure 5: Baseline Real-Time Forecast of Real Refiners' Acquisition Cost as of 2010.12 and Risk Analysis

(a) Alternative Baseline Real-Time Forecasts

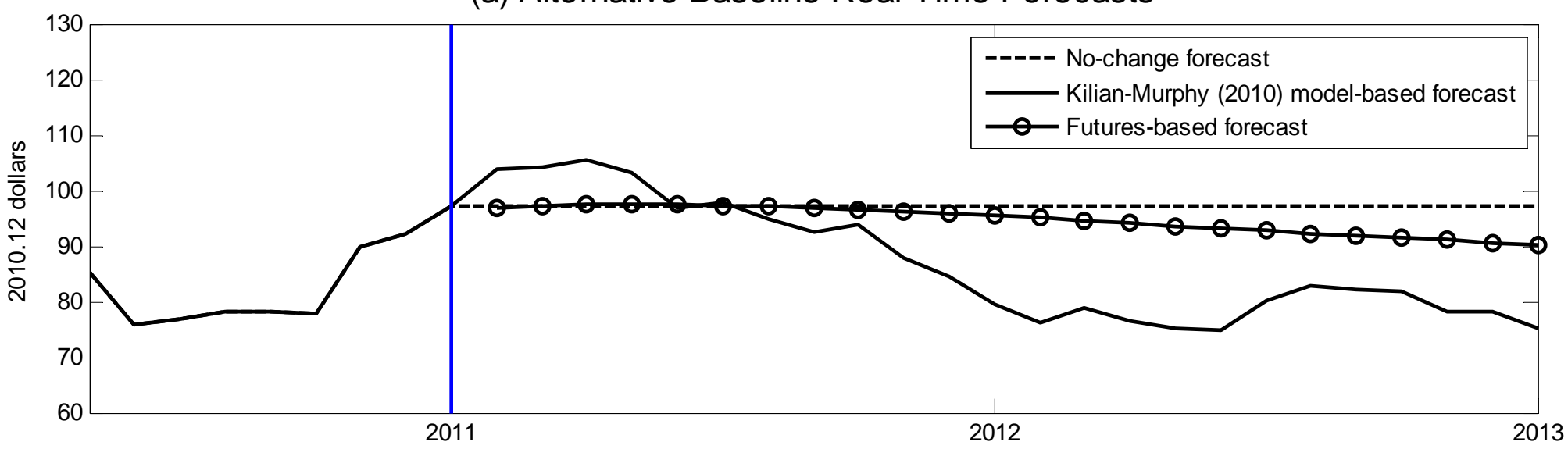

(b) Kilian-Murphy (2010) Model-Based Forecast and Risk Analysis

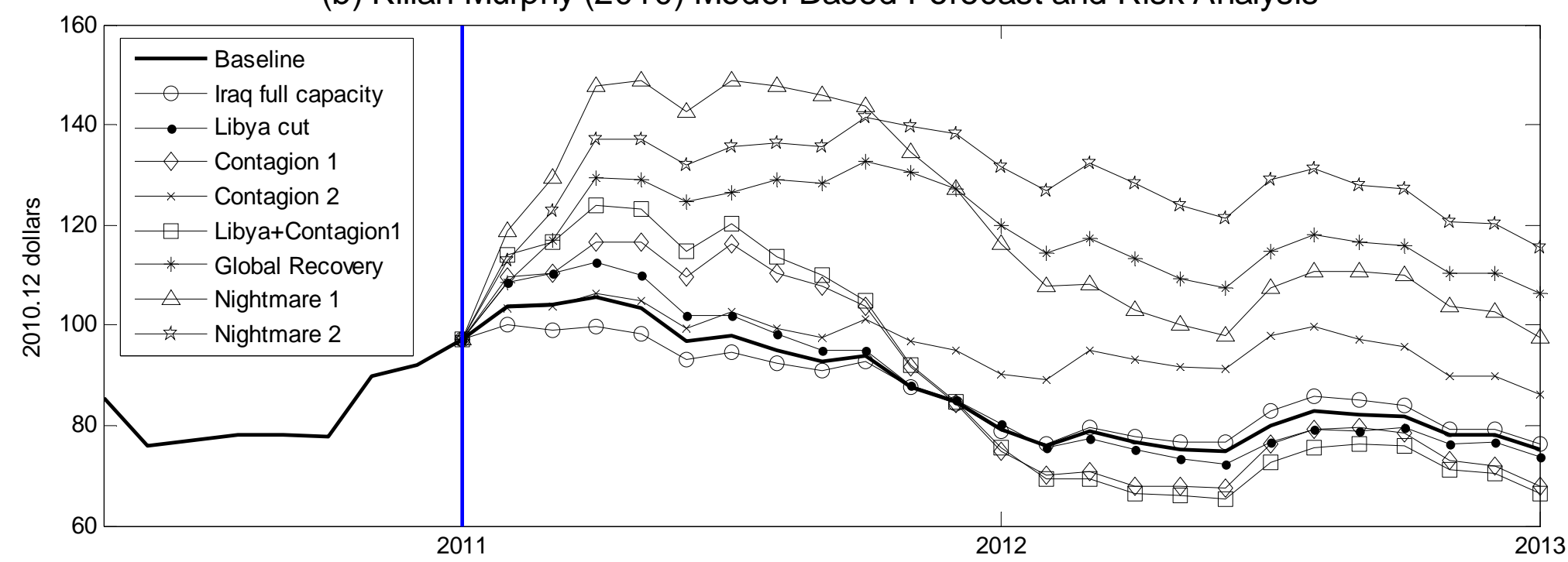

NOTES: The scenarios in panel (b) correspond to those in Figures 3 and 4 . The vertical line indicates the last nowcast. 
Table 1a: Recursive MSPE Ratio Relative to No-Change Forecast of Real U.S. Refiners' Acquisition Cost of Imports Real-Time Data

\begin{tabular}{|c|c|c|c|c|c|c|c|c|c|}
\hline & & \multicolumn{4}{|c|}{$p=12$} & \multicolumn{4}{c|}{$p=24$} \\
\hline Horizon & ARMA(1,1) & AR(p) & VAR(p) & BAR(p) & BVAR(p) & AR(p) & VAR(p) & BAR(p) & BVAR(p) \\
\hline 1 & $\mathbf{0 . 8 9 5}$ & $\mathbf{0 . 8 5 5}$ & $\mathbf{0 . 7 5 0}$ & $\mathbf{0 . 8 5 1}$ & $\mathbf{0 . 7 8 4}$ & $\mathbf{0 . 9 0 8}$ & $\mathbf{0 . 8 6 5}$ & $\mathbf{0 . 8 7 5}$ & $\mathbf{0 . 8 0 6}$ \\
\hline 3 & $\mathbf{0 . 9 0 5}$ & $\mathbf{0 . 9 1 3}$ & $\mathbf{0 . 8 0 8}$ & $\mathbf{0 . 9 0 6}$ & $\mathbf{0 . 8 4 2}$ & $\mathbf{0 . 9 7 8}$ & 1.079 & $\mathbf{0 . 9 2 6}$ & $\mathbf{0 . 8 7 4}$ \\
\hline 6 & $\mathbf{0 . 9 2 8}$ & $\mathbf{1 . 0 0 0}$ & $\mathbf{0 . 9 9 3}$ & $\mathbf{0 . 9 9 3}$ & $\mathbf{0 . 9 9 0}$ & 1.013 & 1.242 & $\mathbf{0 . 9 7 3}$ & 1.004 \\
\hline 9 & $\mathbf{0 . 9 3 3}$ & 1.042 & 1.022 & 1.031 & 1.034 & $\mathbf{0 . 9 9 6}$ & 1.213 & $\mathbf{0 . 9 6 6}$ & 1.045 \\
\hline 12 & $\mathbf{0 . 9 2 1}$ & 1.026 & $\mathbf{0 . 9 7 4}$ & 1.015 & 1.015 & $\mathbf{0 . 9 6 7}$ & 1.294 & $\mathbf{0 . 9 4 6}$ & 1.081 \\
\hline
\end{tabular}

NOTES: Boldface indicates improvements relative to no-change forecast. Horizons are expressed in months. The statistical significance of these results cannot be assessed because none of the currently available tests of equal predictive accuracy applies in this setting. The evaluation window is 1992.1-2010.6.

Table 1b: Recursive Success Ratio Relative to No-Change Forecast of Real U.S. Refiners’ Acquisition Cost of Imports Real-Time Data

\begin{tabular}{|c|c|c|c|c|c|c|c|c|c|}
\hline & & \multicolumn{4}{|c}{$p=12$} & \multicolumn{4}{c|}{$p=24$} \\
\hline Horizon & ARMA(1,1) & AR(p) & VAR(p) & BAR(p) & BVAR(p) & AR(p) & VAR(p) & BAR(p) & BVAR(p) \\
\hline 1 & $\mathbf{0 . 5 4 1}$ & $\mathbf{0 . 5 5 9}^{*}$ & $\mathbf{0 . 5 6 8}^{*}$ & $\mathbf{0 . 5 5 9}^{*}$ & $\mathbf{0 . 5 6 8}^{*}$ & $\mathbf{0 . 5 2 7}^{*}$ & $\mathbf{0 . 5 3 2}^{*}$ & $\mathbf{0 . 5 7 2}^{*}$ & $\mathbf{0 . 6 1 3}^{*}$ \\
\hline 3 & 0.486 & $\mathbf{0 . 5 4 1}^{*}$ & $\mathbf{0 . 5 9 6}^{*}$ & $\mathbf{0 . 5 3 6}$ & $\mathbf{0 . 5 6 8}^{*}$ & $\mathbf{0 . 5 4 1}$ & $\mathbf{0 . 5 6 4}^{* *}$ & $\mathbf{0 . 5 5 5}^{* *}$ & $\mathbf{0 . 6 5 0}^{*}$ \\
\hline 6 & 0.498 & 0.489 & $\mathbf{0 . 5 3 0}^{*}$ & $\mathbf{0 . 5 1 6}$ & $\mathbf{0 . 5 1 6}$ & $\mathbf{0 . 5 2 5}$ & $\mathbf{0 . 5 3 9}$ & $\mathbf{0 . 5 5 8}$ & $\mathbf{0 . 5 8 1}$ \\
\hline 9 & $\mathbf{0 . 5 0 0}$ & 0.425 & $\mathbf{0 . 5 4 2}^{*}$ & 0.430 & $\mathbf{0 . 5 1 4}$ & 0.439 & 0.463 & 0.481 & $\mathbf{0 . 5 5 1}$ \\
\hline 12 & $\mathbf{0 . 5 2 6}$ & 0.483 & $\mathbf{0 . 5 9 7}^{*}$ & 0.493 & $\mathbf{0 . 5 4 5}$ & 0.474 & 0.488 & $\mathbf{0 . 5 0 2}$ & $\mathbf{0 . 5 7 8}$ \\
\hline
\end{tabular}

NOTES: Boldface indicates improvements relative to no-change forecast. ${ }^{*}$ denotes significance at the $5 \%$ level and ${ }^{* *}$ at the $10 \%$ level based on the Pesaran and Timmermann (2009) test for the null hypothesis of no directional accuracy. The evaluation window is 1992.1-2010.6. 
Table 2a: Recursive MSPE Ratio Relative to No-Change Forecast of Real WTI Price Real-Time Data

\begin{tabular}{|c|c|c|c|c|c|c|c|c|c|}
\hline & & \multicolumn{4}{|c|}{$p=12$} & \multicolumn{4}{c|}{$p=24$} \\
\hline Horizon & ARMA(1,1) & AR(p) & VAR(p) & BAR(p) & BVAR(p) & AR(p) & VAR(p) & BAR(p) & BVAR(p) \\
\hline 1 & $\mathbf{0 . 9 1 7}$ & $\mathbf{0 . 9 3 5}$ & $\mathbf{0 . 8 8 2}$ & $\mathbf{0 . 9 2 4}$ & $\mathbf{0 . 8 8 1}$ & $\mathbf{0 . 9 6 1}$ & 1.124 & $\mathbf{0 . 9 0 4}$ & $\mathbf{0 . 8 6 4}$ \\
\hline 3 & $\mathbf{0 . 9 3 6}$ & $\mathbf{0 . 9 7 6}$ & $\mathbf{0 . 9 2 5}$ & $\mathbf{0 . 9 6 5}$ & $\mathbf{0 . 9 1 3}$ & $\mathbf{0 . 9 4 0}$ & 1.239 & $\mathbf{0 . 9 0 8}$ & $\mathbf{0 . 8 6 9}$ \\
\hline 6 & $\mathbf{0 . 9 3 5}$ & 1.034 & 1.035 & 1.016 & 1.000 & $\mathbf{0 . 9 4 2}$ & 1.230 & $\mathbf{0 . 9 2 5}$ & $\mathbf{0 . 9 3 8}$ \\
\hline 9 & $\mathbf{0 . 9 2 7}$ & 1.051 & 1.035 & 1.027 & 1.022 & $\mathbf{0 . 9 2 1}$ & 1.119 & $\mathbf{0 . 9 1 5}$ & $\mathbf{0 . 9 4 5}$ \\
\hline 12 & $\mathbf{0 . 9 1 7}$ & 1.029 & $\mathbf{0 . 9 8 7}$ & 1.005 & 1.001 & $\mathbf{0 . 9 0 0}$ & 1.120 & $\mathbf{0 . 8 9 7}$ & $\mathbf{0 . 9 5 2}$ \\
\hline
\end{tabular}

NOTES: See Table $1 \mathrm{a}$.

Table 2b: Recursive Success Ratio Relative to No-Change Forecast of Real WTI Price Real-Time Data

\begin{tabular}{|c|c|c|c|c|c|c|c|c|c|}
\hline & & \multicolumn{4}{|c|}{$p=12$} & \multicolumn{4}{c|}{$p=24$} \\
\hline Horizon & ARMA(1,1) & AR(p) & VAR(p) & BAR(p) & BVAR(p) & AR(p) & VAR(p) & BAR(p) & BVAR(p) \\
\hline 1 & 0.496 & 0.496 & $\mathbf{0 . 5 5 0}^{*}$ & 0.478 & $\mathbf{0 . 5 3 6}$ & 0.491 & 0.487 & $\mathbf{0 . 5 0 9}$ & $\mathbf{0 . 5 5 9}^{* *}$ \\
\hline 3 & 0.482 & $\mathbf{0 . 5 2 3}$ & $\mathbf{0 . 6 0 5}^{*}$ & $\mathbf{0 . 5 0 5}$ & $\mathbf{0 . 5 7 7}^{* *}$ & $\mathbf{0 . 5 0 5}$ & $\mathbf{0 . 6 1 4}$ & $\mathbf{0 . 5 0 5}$ & $\mathbf{0 . 6 0 5}^{*}$ \\
\hline 6 & 0.465 & 0.447 & $\mathbf{0 . 5 2 5}^{*}$ & 0.452 & $\mathbf{0 . 5 5 3}$ & 0.498 & $\mathbf{0 . 5 6 7}$ & 0.461 & $\mathbf{0 . 5 9 0}$ \\
\hline 9 & 0.467 & 0.416 & $\mathbf{0 . 5 1 9}^{*}$ & 0.425 & $\mathbf{0 . 5 5 1}$ & 0.463 & 0.495 & 0.463 & $\mathbf{0 . 5 6 4}^{*}$ \\
\hline 12 & $\mathbf{0 . 5 0 7}$ & 0.465 & $\mathbf{0 . 6 1 1}^{*}$ & 0.460 & $\mathbf{0 . 5 3 6}$ & 0.488 & 0.498 & 0.488 & $\mathbf{0 . 6 1 1}^{*}$ \\
\hline
\end{tabular}

NOTES: See Table 1b. 
Table 3a: Recursive MSPE Ratio Relative to No-Change Forecast of Real U.S. Refiners’ Acquisition Cost of Imports Ex-Post Revised Data

\begin{tabular}{|c|c|c|c|c|c|c|c|c|c|}
\hline & & \multicolumn{4}{|c|}{$p=12$} & \multicolumn{4}{c|}{$p=24$} \\
\hline Horizon & ARMA(1,1) & AR(p) & VAR(p) & BAR(p) & BVAR(p) & AR(p) & VAR(p) & BAR(p) & BVAR(p) \\
\hline 1 & $\mathbf{0 . 7 8 1}^{*}$ & $\mathbf{0 . 7 5 8}^{*}$ & $\mathbf{0 . 6 7 4}^{*}$ & $\mathbf{0 . 7 5 8}^{*}$ & $\mathbf{0 . 7 2 2}^{*}$ & $\mathbf{0 . 8 0 7}^{*}$ & $\mathbf{0 . 8 4 2}^{*}$ & $\mathbf{0 . 7 6 8}^{*}$ & $\mathbf{0 . 7 3 5}^{*}$ \\
\hline 3 & $\mathbf{0 . 8 8 7}^{*}$ & $\mathbf{0 . 8 8 6}^{*}$ & $\mathbf{0 . 7 8 2}^{*}$ & $\mathbf{0 . 8 8 1}^{*}$ & $\mathbf{0 . 8 3 3}^{*}$ & $\mathbf{0 . 9 3 1}^{*}$ & 1.049 & $\mathbf{0 . 8 8 2}^{*}$ & $\mathbf{0 . 8 4 8}^{*}$ \\
\hline 6 & $\mathbf{0 . 9 2 2}^{*}$ & $\mathbf{0 . 9 8 3}^{*}$ & $\mathbf{0 . 9 4 3}^{*}$ & $\mathbf{0 . 9 7 7}^{*}$ & $\mathbf{0 . 9 7 0}^{*}$ & $\mathbf{0 . 9 8 8}^{*}$ & 1.117 & $\mathbf{0 . 9 4 9}^{*}$ & $\mathbf{0 . 9 7 0}^{*}$ \\
\hline 9 & $\mathbf{0 . 9 2 6}^{*}$ & 1.033 & 1.025 & 1.023 & 1.037 & $\mathbf{0 . 9 8 8}^{*}$ & 1.190 & $\mathbf{0 . 9 5 8}^{*}$ & 1.044 \\
\hline 12 & $\mathbf{0 . 9 1 6}^{*}$ & 1.021 & $\mathbf{1 . 0 0 0}^{* *}$ & 1.010 & 1.021 & $\mathbf{0 . 9 5 7}^{*}$ & 1.282 & $\mathbf{0 . 9 3 5}^{*}$ & 1.079 \\
\hline
\end{tabular}

NOTES: Boldface indicates improvements relative to no-change forecast. Horizons are expressed in months. ${ }^{*}$ denotes significance at the $5 \%$ level and ${ }^{* *}$ at the $10 \%$ level based on bootstrap critical values for the average loss differential. The evaluation window is 1992.1-2010.6.

Table 3b: Recursive Success Ratio Relative to No-Change Forecast of Real U.S. Refiners' Acquisition Cost of Imports Ex-Post Revised Data

\begin{tabular}{|c|c|c|c|c|c|c|c|c|c|}
\hline & & \multicolumn{4}{|c|}{$p=12$} & \multicolumn{4}{c|}{$p=24$} \\
\hline Horizon & ARMA(1,1) & AR(p) & VAR(p) & BAR(p) & BVAR(p) & AR(p) & VAR(p) & BAR(p) & BVAR(p) \\
\hline 1 & $\mathbf{0 . 5 6 8}^{*}$ & $\mathbf{0 . 5 9 9}^{*}$ & $\mathbf{0 . 5 7 7}^{*}$ & $\mathbf{0 . 5 9 0}^{*}$ & $\mathbf{0 . 5 6 3}^{*}$ & $\mathbf{0 . 5 5 9}^{* *}$ & $\mathbf{0 . 5 4 5}$ & $\mathbf{0 . 6 0 4}^{*}$ & $\mathbf{0 . 6 1 7}^{*}$ \\
\hline 3 & 0.500 & $\mathbf{0 . 5 4 1}^{*}$ & $\mathbf{0 . 5 6 4}^{* *}$ & $\mathbf{0 . 5 4 6}^{*}$ & $\mathbf{0 . 5 7 7}^{*}$ & $\mathbf{0 . 5 5 9}^{*}$ & $\mathbf{0 . 6 1 4}^{*}$ & $\mathbf{0 . 5 6 8}^{*}$ & $\mathbf{0 . 6 5 9 9}^{*}$ \\
\hline 6 & 0.489 & $\mathbf{0 . 5 1 2}$ & 0.489 & $\mathbf{0 . 5 1 6}$ & $\mathbf{0 . 5 3 0}^{* *}$ & $\mathbf{0 . 5 6 7}^{* *}$ & $\mathbf{0 . 5 8 1}^{* *}$ & $\mathbf{0 . 5 5 8}$ & $\mathbf{0 . 6 0 4}^{*}$ \\
\hline 9 & 0.491 & 0.430 & $\mathbf{0 . 5 1 4}^{*}$ & 0.421 & 0.486 & 0.435 & 0.491 & 0.486 & $\mathbf{0 . 5 6 1}$ \\
\hline 12 & $\mathbf{0 . 5 1 7}$ & 0.483 & $\mathbf{0 . 5 7 4}^{* *}$ & 0.493 & $\mathbf{0 . 5 2 1}$ & 0.488 & 0.483 & 0.493 & $\mathbf{0 . 5 8 8}$ \\
\hline
\end{tabular}

NOTES: Boldface indicates improvements relative to no-change forecast. ${ }^{*}$ denotes significance at the $5 \%$ level and ${ }^{* *}$ at the $10 \%$ level based on the Pesaran and Timmermann (2009) test for the null hypothesis of no directional accuracy. The evaluation window is 1992.1-2010.6. 
Table 4a: Recursive MSPE Ratio Relative to No-Change Forecast of Real WTI Price Ex-Post Revised Data

\begin{tabular}{|c|c|c|c|c|c|c|c|c|c|}
\hline & & \multicolumn{4}{|c|}{$p=12$} & \multicolumn{4}{c|}{$p=24$} \\
\hline Horizon & ARMA(1,1) & AR(p) & VAR(p) & BAR(p) & BVAR(p) & AR(p) & VAR(p) & BAR(p) & BVAR(p) \\
\hline 1 & $\mathbf{0 . 9 1 0}^{*}$ & $\mathbf{0 . 9 2 6}^{*}$ & $\mathbf{0 . 8 4 2}^{*}$ & $\mathbf{0 . 9 1 6}^{*}$ & $\mathbf{0 . 8 7 0}^{*}$ & $\mathbf{0 . 9 4 9}^{*}$ & 1.089 & $\mathbf{0 . 8 9 3}^{*}$ & $\mathbf{0 . 8 5 2}^{*}$ \\
\hline 3 & $\mathbf{0 . 9 3 5}^{*}$ & $\mathbf{0 . 9 7 4}^{*}$ & $\mathbf{0 . 8 8 6}^{*}$ & $\mathbf{0 . 9 6 3}^{*}$ & $\mathbf{0 . 9 0 7}^{*}$ & $\mathbf{0 . 9 3 8}^{*}$ & 1.217 & $\mathbf{0 . 9 0 5}^{*}$ & $\mathbf{0 . 8 6 0}^{*}$ \\
\hline 6 & $\mathbf{0 . 9 3 5}^{*}$ & 1.034 & 1.004 & 1.015 & $\mathbf{0 . 9 9 1}^{*}$ & $\mathbf{0 . 9 4 1}^{*}$ & 1.199 & $\mathbf{0 . 9 2 4}^{*}$ & $\mathbf{0 . 9 1 8}^{*}$ \\
\hline 9 & $\mathbf{0 . 9 2 7}^{*}$ & 1.050 & 1.043 & 1.026 & 1.028 & $\mathbf{0 . 9 1 9}^{*}$ & 1.087 & $\mathbf{0 . 9 1 3}^{*}$ & ..941 $^{*}$ \\
\hline 12 & $\mathbf{0 . 9 1 9}^{*}$ & 1.028 & 1.009 & 1.004 & 1.008 & $\mathbf{0 . 8 9 8}^{*}$ & 1.107 & $\mathbf{0 . 8 9 5}^{*}$ & 0.952 $^{*}$ \\
\hline
\end{tabular}

NOTES: See Table 3a.

Table 4b: Recursive Success Ratio Relative to No-Change Forecast of Real WTI Price Ex-Post Revised Data

\begin{tabular}{|c|c|c|c|c|c|c|c|c|c|}
\hline & & \multicolumn{4}{|c|}{$p=12$} & \multicolumn{4}{c|}{$p=24$} \\
\hline Horizon & ARMA(1,1) & AR(p) & VAR(p) & BAR(p) & BVAR(p) & AR(p) & VAR(p) & BAR(p) & BVAR(p) \\
\hline 1 & 0.500 & 0.491 & $\mathbf{0 . 5 2 7}$ & 0.491 & $\mathbf{0 . 5 3 6}$ & 0.487 & $\mathbf{0 . 5 1 8}$ & $\mathbf{0 . 5 0 9}$ & $\mathbf{0 . 5 4 1}$ \\
\hline 3 & 0.486 & $\mathbf{0 . 5 2 3}$ & $\mathbf{0 . 5 4 6}$ & $\mathbf{0 . 5 1 4}$ & $\mathbf{0 . 5 4 6}$ & $\mathbf{0 . 5 0 9}$ & $\mathbf{0 . 5 9 6}^{*}$ & $\mathbf{0 . 5 0 9}$ & $\mathbf{0 . 6 1 4}$ \\
\hline 6 & 0.465 & 0.447 & $\mathbf{0 . 5 0 2}$ & 0.452 & $\mathbf{0 . 5 3 5}$ & 0.498 & $\mathbf{0 . 5 3 5}$ & 0.461 & $\mathbf{0 . 5 8 5}$ \\
\hline 9 & 0.467 & 0.421 & $\mathbf{0 . 5 1 9}$ & 0.425 & 0.497 & 0.472 & 0.495 & 0.463 & $\mathbf{0 . 5 7 0}$ \\
\hline 12 & $\mathbf{0 . 5 0 7}$ & 0.465 & $\mathbf{0 . 5 5 5}$ & 0.465 & $\mathbf{0 . 5 1 2}$ & 0.488 & 0.483 & 0.488 & $\mathbf{0 . 5 8 3}$ \\
\hline
\end{tabular}

NOTES: See Table 3b. 
Table 5: One-Month Ahead Forecast Accuracy of BVAR(24) Model

All Real-Time Data Except for One Time Series at a Time

\section{Recursive MSPE Ratio Relative to No-Change Forecast}

Ex-post revised data for:

U.S. Refiners’ Acquisition Cost WTI

None of the time series

for Imports

Global oil production

0.806

0.864

Global real economic activity

0.806

0.866

U.S. consumer price index

0.807

0.864

Global oil inventories

0.798

0.851

U.S. oil inventories

0.803

0.863

Real price of oil

0.811

0.880

Nominal price of oil

0.739

0.851

0.760

0.864

All time series

0.735

0.852

NOTES: See Table 1. 
Table 6: Accuracy of Alternative Forecasting Methods Relative to No-Change Forecast

(a) Real-Time Data

\begin{tabular}{|c|c|c|c|c|c|c|c|c|}
\hline & \multicolumn{2}{|c|}{ Refiners' Acquisition Cost for Imports } & \multicolumn{4}{c|}{ WTI } \\
\hline & $\begin{array}{c}\text { Oil Futures-Based } \\
\text { Model }\end{array}$ & \multicolumn{2}{c|}{$\begin{array}{c}\text { Commodity Price } \\
\text { Based Model }\end{array}$} & $\begin{array}{l}\text { Oil Futures-Based } \\
\text { Model }\end{array}$ & $\begin{array}{l}\text { Commodity Price } \\
\text { Based Model }\end{array}$ \\
\hline Horizon & MSPE & $\begin{array}{l}\text { Success } \\
\text { Ratio }\end{array}$ & MSPE & $\begin{array}{l}\text { Success } \\
\text { Ratio }\end{array}$ & MSPE & $\begin{array}{l}\text { Success } \\
\text { Ratio }\end{array}$ & MSPE & $\begin{array}{l}\text { Success } \\
\text { Ratio }\end{array}$ \\
\hline 1 & $\mathbf{0 . 9 9 7}$ & 0.441 & $\mathbf{0 . 8 2 4}$ & $\mathbf{0 . 5 6 8}^{*}$ & 1.004 & 0.460 & $\mathbf{0 . 8 2 0}^{* *}$ & $\mathbf{0 . 5 5 0}^{* *}$ \\
\hline 3 & $\mathbf{0 . 9 8 1}$ & 0.491 & $\mathbf{0 . 7 6 3}^{\text {** }}$ & $\mathbf{0 . 6 3 2}^{*}$ & $\mathbf{0 . 9 9 9}$ & 0.477 & $\mathbf{0 . 7 4 4}^{* *}$ & $\mathbf{0 . 6 0 9}^{*}$ \\
\hline 6 & $\mathbf{0 . 9 8 7}$ & $\mathbf{0 . 5 0 2}^{*}$ & 1.046 & $\mathbf{0 . 6 0 8}^{*}$ & 1.002 & $\mathbf{0 . 5 0 2}^{*}$ & 1.040 & $\mathbf{0 . 5 9 0}^{*}$ \\
\hline 9 & $\mathbf{0 . 9 6 6}$ & $\mathbf{0 . 5 5 1}^{*}$ & 1.101 & $\mathbf{0 . 5 5 1}^{* *}$ & $\mathbf{0 . 9 8 1}$ & $\mathbf{0 . 5 4 7}^{*}$ & 1.099 & $\mathbf{0 . 5 6 5}^{* *}$ \\
\hline 12 & $\mathbf{0 . 9 1 2}$ & $\mathbf{0 . 5 6 9}^{*}$ & 1.107 & $\mathbf{0 . 5 5 5}^{* *}$ & $\mathbf{0 . 9 3 2}$ & $\mathbf{0 . 5 5 9}^{*}$ & 1.112 & $\mathbf{0 . 5 7 4}^{* *}$ \\
\hline
\end{tabular}

(b) Ex-Post Revised Data

\begin{tabular}{|c|c|c|c|c|c|c|c|c|}
\hline \multirow[b]{3}{*}{ Horizon } & \multicolumn{4}{|c|}{ Refiners’ Acquisition Cost for Imports } & \multicolumn{4}{|c|}{ WTI } \\
\hline & \multicolumn{2}{|c|}{$\begin{array}{c}\text { Oil Futures-Based } \\
\text { Model }\end{array}$} & \multicolumn{2}{|c|}{$\begin{array}{l}\text { Commodity Price } \\
\text { Based Model }\end{array}$} & \multicolumn{2}{|c|}{$\begin{array}{c}\text { Oil Futures-Based } \\
\text { Model }\end{array}$} & \multicolumn{2}{|c|}{$\begin{array}{c}\text { Commodity Price } \\
\text { Based Model }\end{array}$} \\
\hline & MSPE & $\begin{array}{l}\text { Success } \\
\text { Ratio }\end{array}$ & MSPE & $\begin{array}{l}\text { Success } \\
\text { Ratio }\end{array}$ & MSPE & \begin{tabular}{|l} 
Success \\
Ratio
\end{tabular} & MSPE & $\begin{array}{l}\text { Success } \\
\text { Ratio }\end{array}$ \\
\hline 1 & 1.001 & 0.44 & 0.7 & $0.568^{*}$ & 1.003 & 60 & 0.8 & $0.550^{* *}$ \\
\hline 3 & 0.987 & 0.4 & $0.759^{*}$ & $2^{*}$ & 0.999 & 0. & $0.739^{* *}$ & $0.609^{*}$ \\
\hline 6 & 0.990 & 0.5 & 1.048 & $0.608^{*}$ & 1.002 & $\mathbf{0 .}$ & 1.038 & $0.590^{*}$ \\
\hline 9 & 0.966 & 0.5 & 1.108 & 0.551 & 0.981 & $0.547^{*}$ & 1.099 & $0.565^{* *}$ \\
\hline 12 & 0.911 & $0.569^{*}$ & 1.116 & $0.555^{* *}$ & 0.931 & $0.559^{*}$ & 1.112 & $0.574^{* *}$ \\
\hline
\end{tabular}

NOTES: Boldface indicates improvements relative to no-change forecast. ${ }^{*}$ denotes significance at the $5 \%$ level and ${ }^{* *}$ at the $10 \%$ level based on the Diebold and Mariano (1995) test of equal predictive accuracy and the Pesaran and Timmermann (2009) test for the null hypothesis of no directional accuracy. The evaluation window is 1992.1-2010.6. 